Supplement of Atmos. Chem. Phys., 15, 11355-11371, 2015

http://www.atmos-chem-phys.net/15/11355/2015/

doi:10.5194/acp-15-11355-2015-supplement

(C) Author(s) 2015. CC Attribution 3.0 License.

(c) (1)

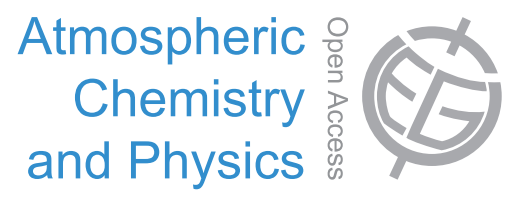

Supplement of

\title{
Sources and chemical characterization of organic aerosol during the summer in the eastern Mediterranean
}

\section{E. Kostenidou et al.}

Correspondence to: S. N. Pandis (spyros@ @ chemeng.upatras.gr)

The copyright of individual parts of the supplement might differ from the CC-BY 3.0 licence. 


\section{Locations of the sampling sites.}

The two campaigns were conducted in Patras and Athens. Figures S1 and S2 show the locations of the two sampling stations.

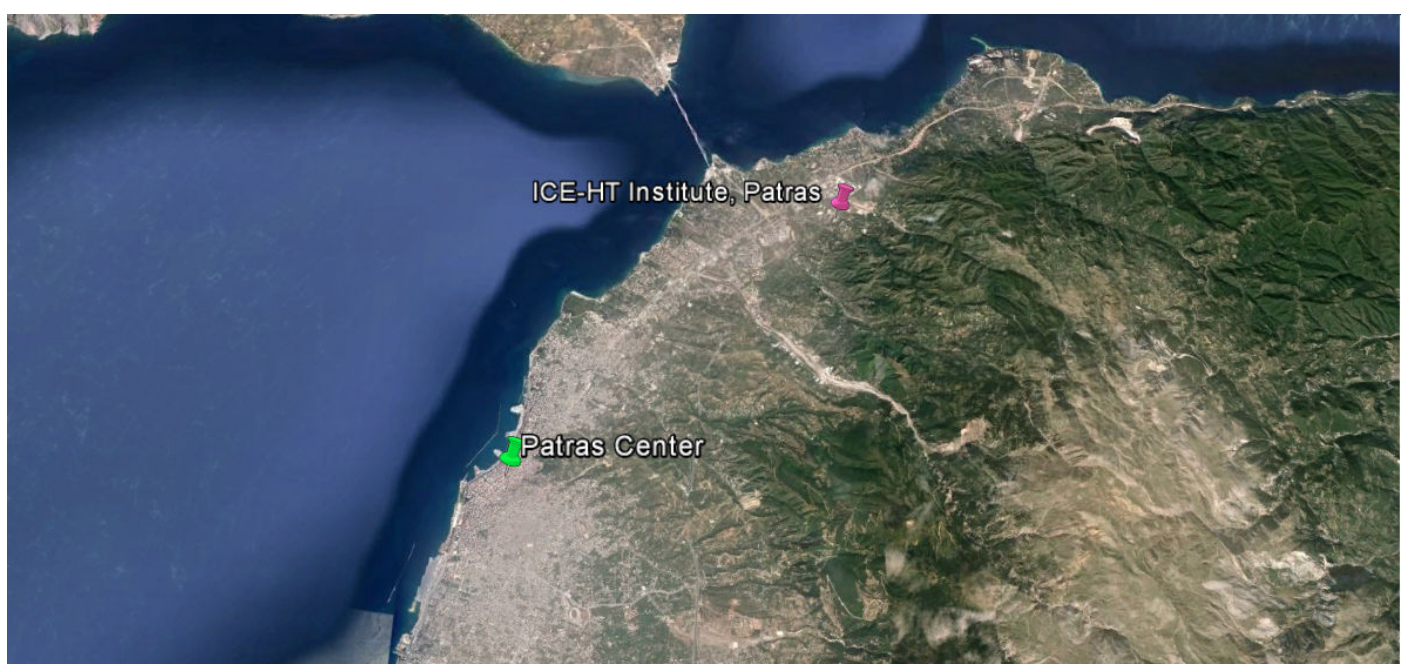

Figure S1. The two sampling sites in Patras. All the measurements described in this paper were collected at the ICE-HT site, $8 \mathrm{~km}$ away from the city center.

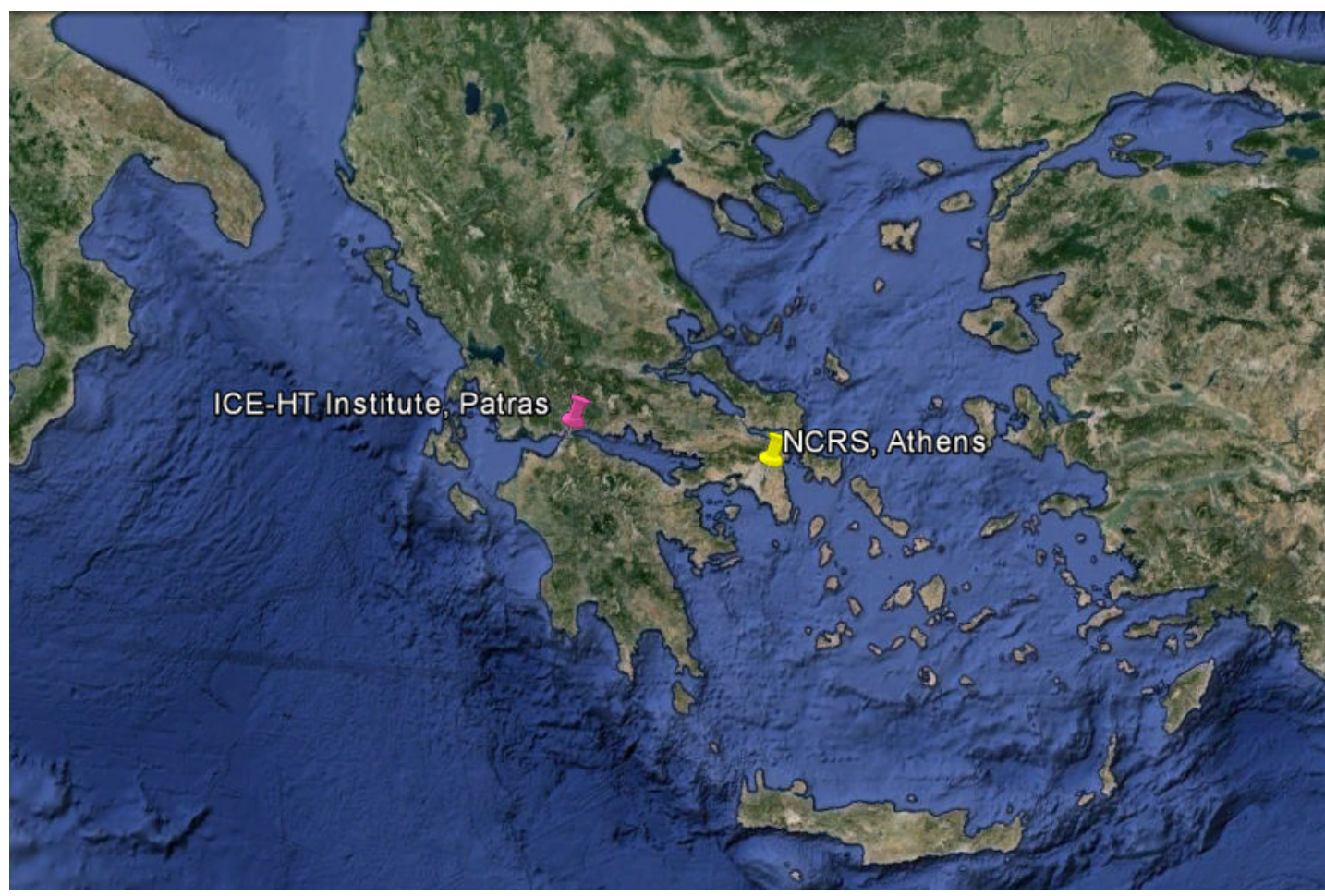

Figure S2. Map of the positions of the Patras and Athens sampling sites. The distance between the two cities is around $200 \mathrm{~km}$. 


\section{CE estimation}

For the CE estimation we applied the algorithm of Kostenidou et al. (2007) that combines AMS and SMPS distributions. The organic density is also calculated from the same algorithm. We modified the above code inserting the shape factor $(\chi)$ and we executed it for various shape factors. Then we selected the minimum of the errors scores which corresponds to the optimum triplet of CE, organic density and shape factor.

\section{A. Patras}

Figure $\mathrm{S} 3$ shows the $\mathrm{CE}$ and the organic density for $\chi=1-1.2$. The organic density is quite sensitive to different shape factors, while CE changes significantly only for $\chi>1.1$. Selecting the solution that corresponds to the minimum error score and after removing the spikes (for error score $>0.2$ ) the organic density becomes noisy with high values (above $2 \mathrm{~g} \mathrm{~cm}^{-3}$ ) (Figure S4a). Thus, for the CE and organic density determination we used a shape factor equals to 1 for the Patras data set (Figure S4b and S4c). In this case the organic density is more smoothed and has more meaningful values. Figure S5 illustrates the correlation between the $\mathrm{PM}_{1}$ AMS sulphate (after CE corrections) and the $\mathrm{PM}_{2.5}$ filter sulphate measurements.

\section{B. Athens}

For the Athens data we tested various shape factors in the range 1-1.6. Figure S6 depicts the $\mathrm{CE}$ and the organic density for $\chi=1-1.6$. As in Patras the organic density is sensitive to the shape factor, while CE changes dramatically for $\chi>1.3$. Choosing the solution that corresponds to the minimum error score (and after scavenging the spikes for error score $>0.2$ ) we obtain the optimum organic density (Figure S7a), with an average value $1.15 \pm 0.36 \mathrm{~g} \mathrm{~cm}^{-3}$. If a shape factor of 1 is used the average organic density becomes 0.66 $\mathrm{g} \mathrm{cm}^{-3}$, which is quite low. The optimum CE and $\chi$ are illustrated in Figures S7b and S7c. If a $\chi=1$ was used then the average $\mathrm{CE}$ would be 0.59 . Figure $\mathrm{S} 8$ shows the correlation between the $\mathrm{PM}_{2.5}$ filter sulphate and the CE corrected $\mathrm{PM}_{1} \mathrm{AMS}$ sulphate measurements. 

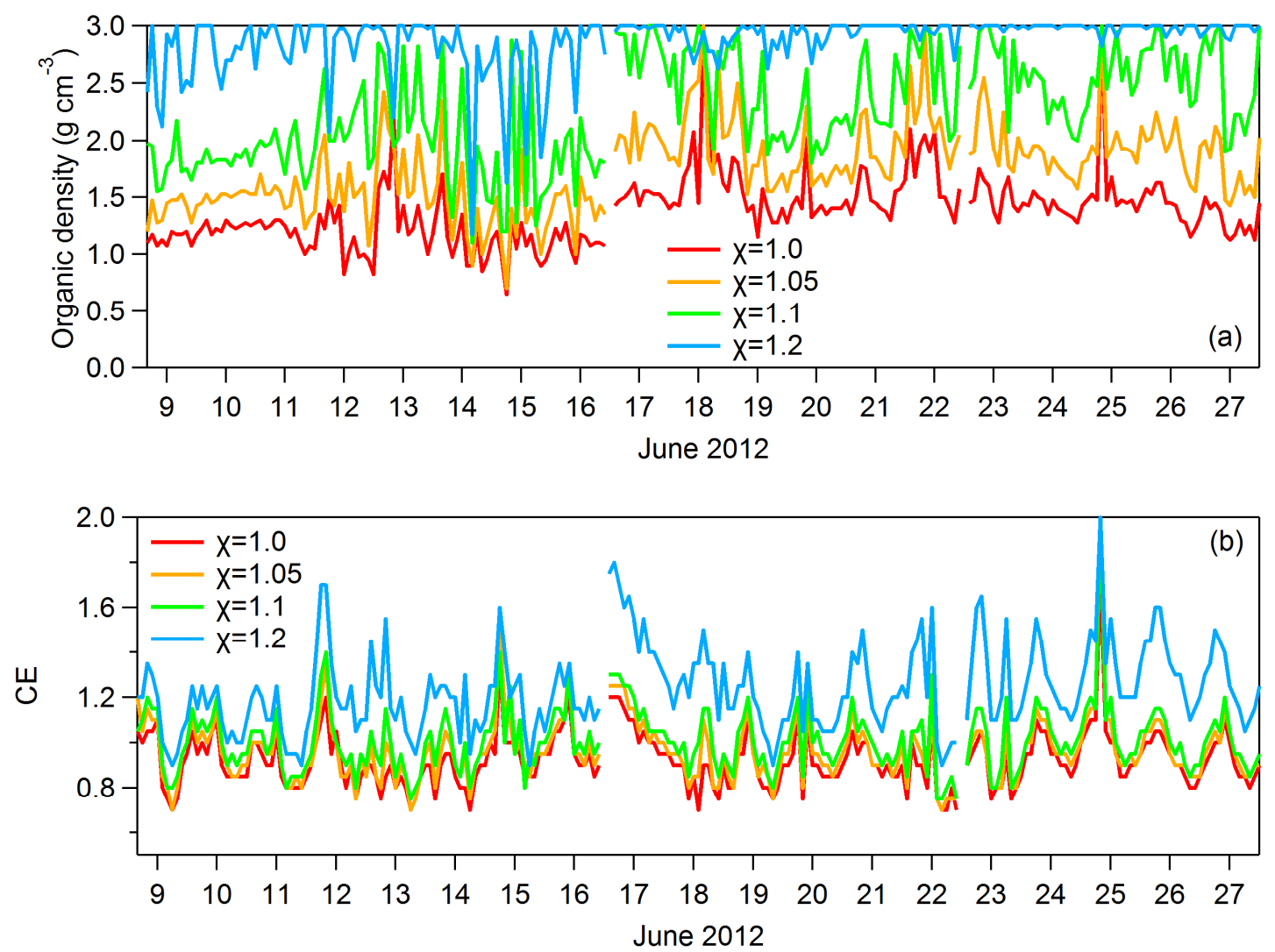

Figure S3. The organic density (a) is sensitive to the shape factor, while CE (b) practically changes for $\chi$ greater than 1.1 (Patras). 

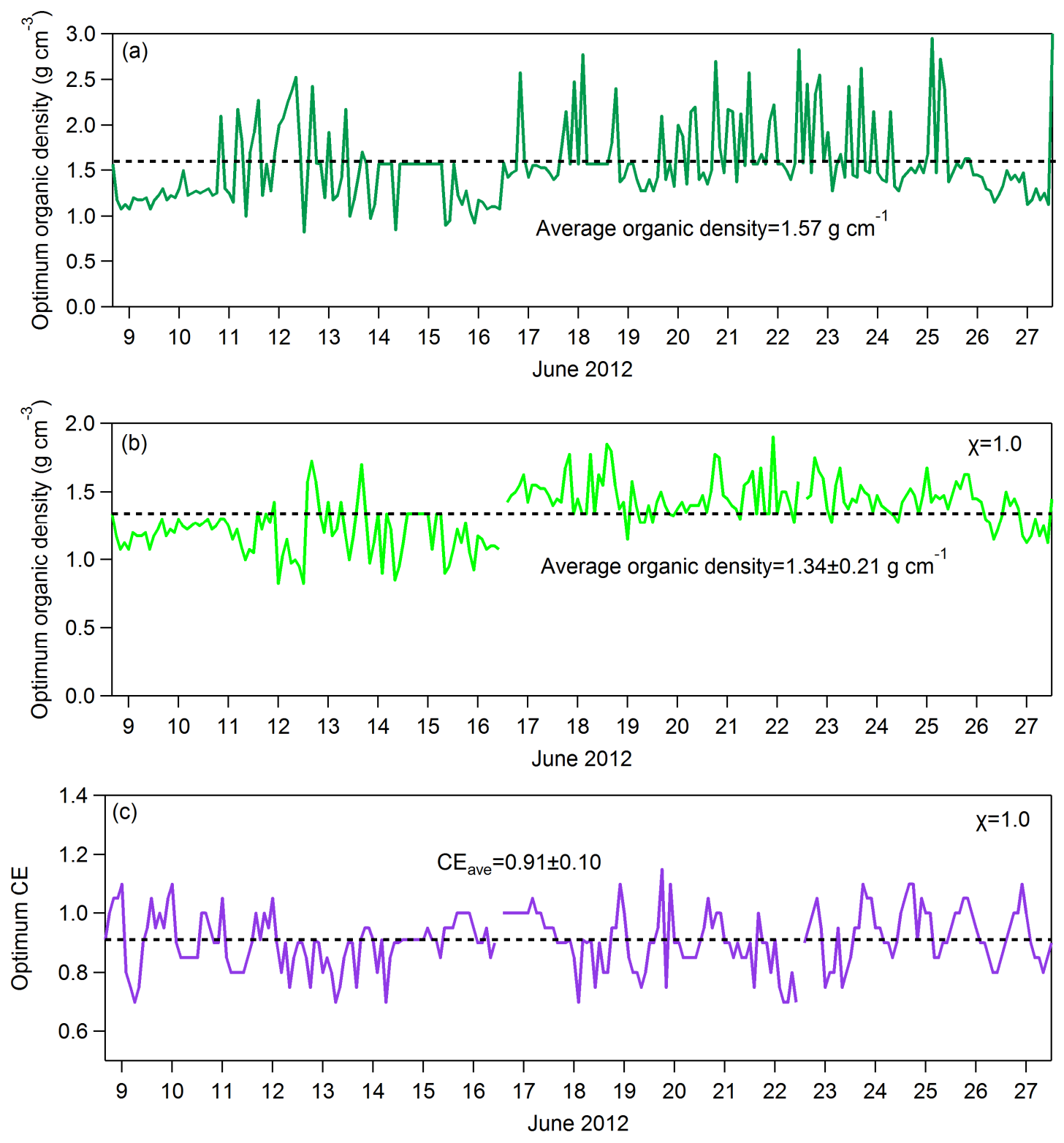

Figure S4. Selecting the solution that corresponds to the minimum error score and after removing the spikes (for error score $>0.2$ ) the organic density becomes noisy with values higher than $2 \mathrm{~g} \mathrm{~cm}^{-3}$ (a). Thus we calculated he organic density for $\chi=1$ (b) and the CE for $\chi=1$ (c) (Patras). 


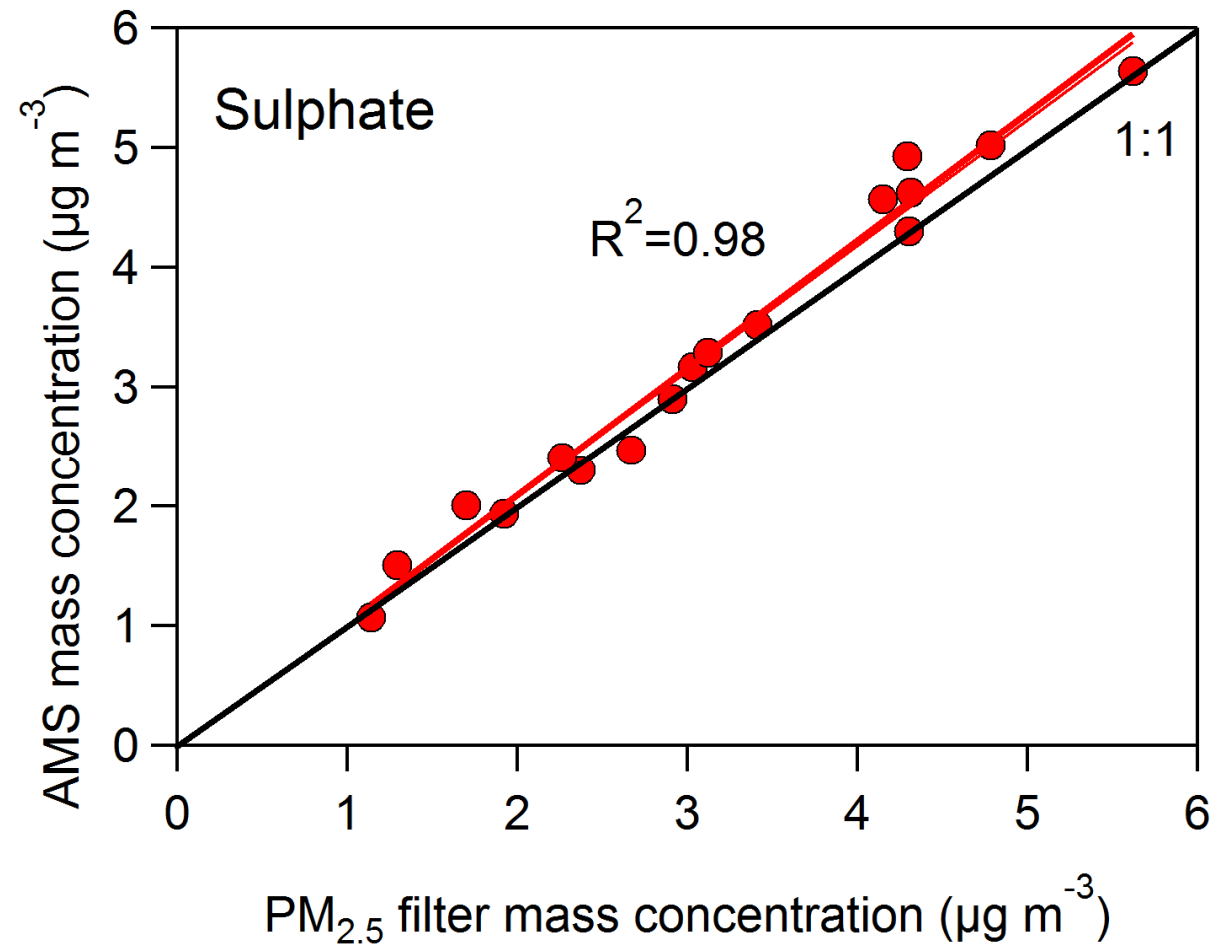

Figure S5. Comparison of the sulphate mass concentration between the $\mathrm{PM}_{1}$ AMS (after the $\mathrm{CE}$ correction) and the $\mathrm{PM}_{2.5}$ filters measurements (Patras). The $\mathrm{R}^{2}$ is 0.98 (slope $=1.05$, intercept $=-0.0095$ ), which suggests that there was relatively little sulphate in the $1-2.5 \mu \mathrm{m}$ size range. 

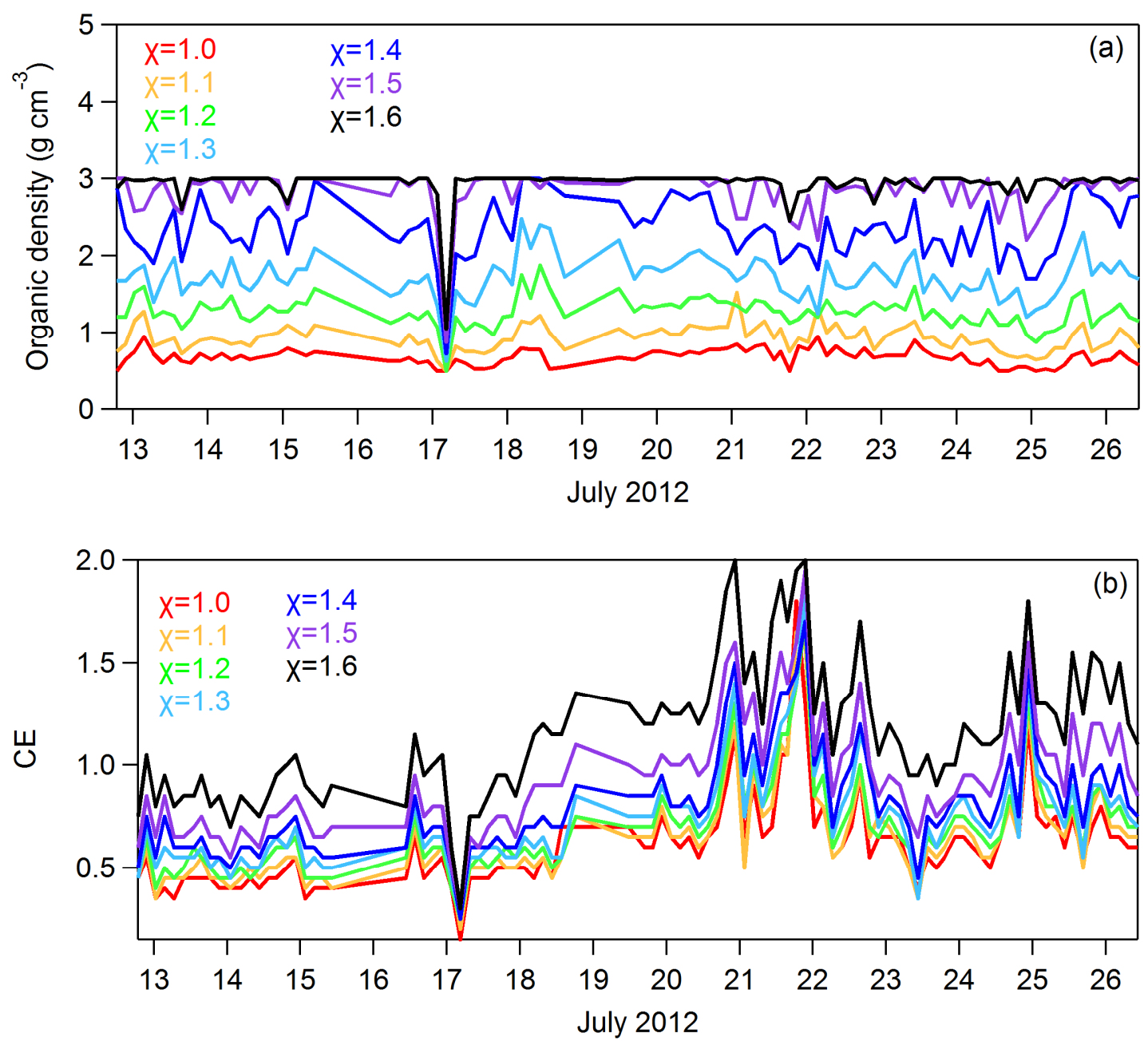

Figure S6. The organic density (a) is quite sensitive to the shape factor, while CE (b) changes for $\chi$ greater than 1.3 (Athens). 

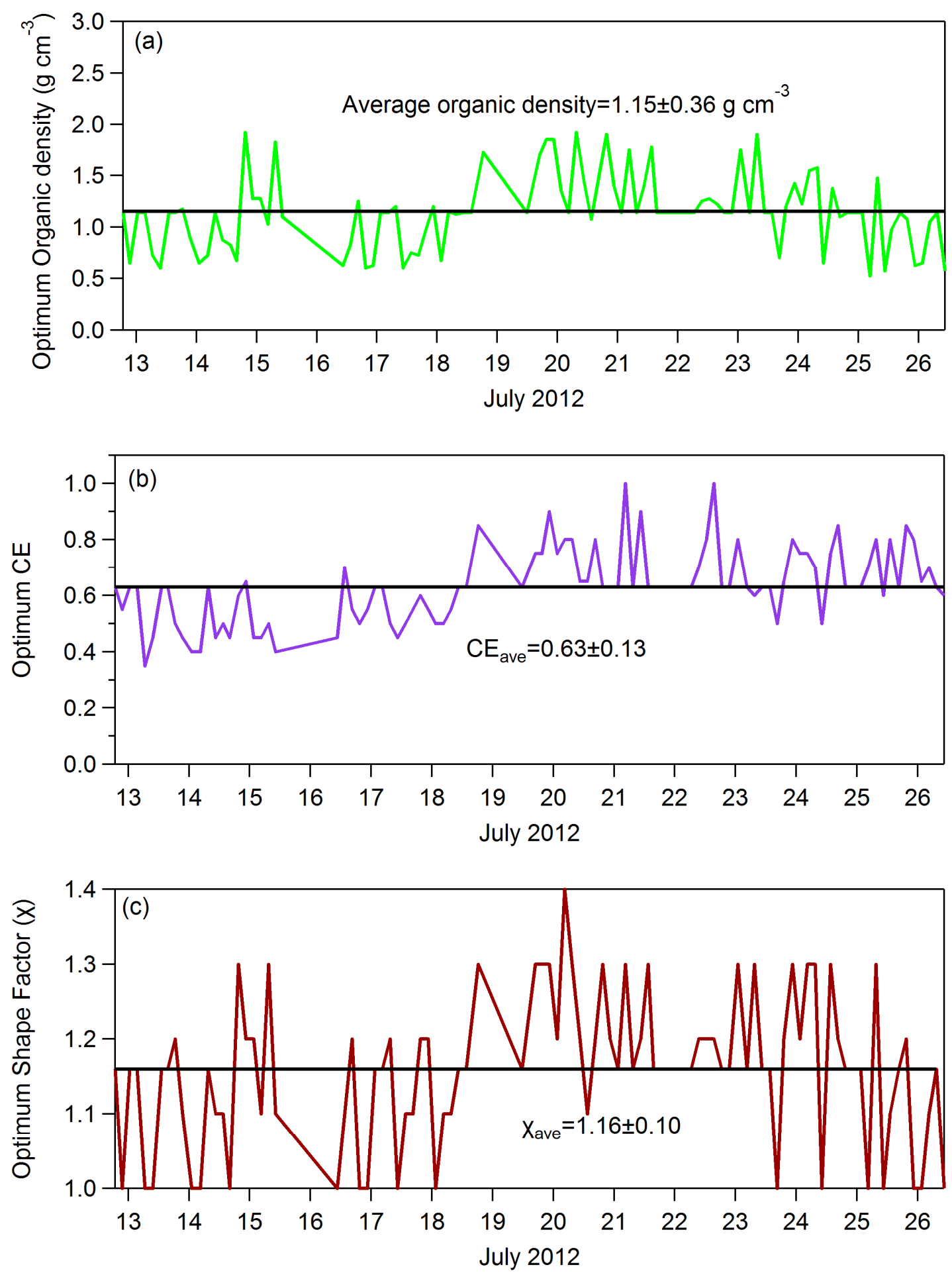

Figure S7. (a)The optimum organic density; (b) CE and (c) shape factor $\chi$ for the Athens campaign. 


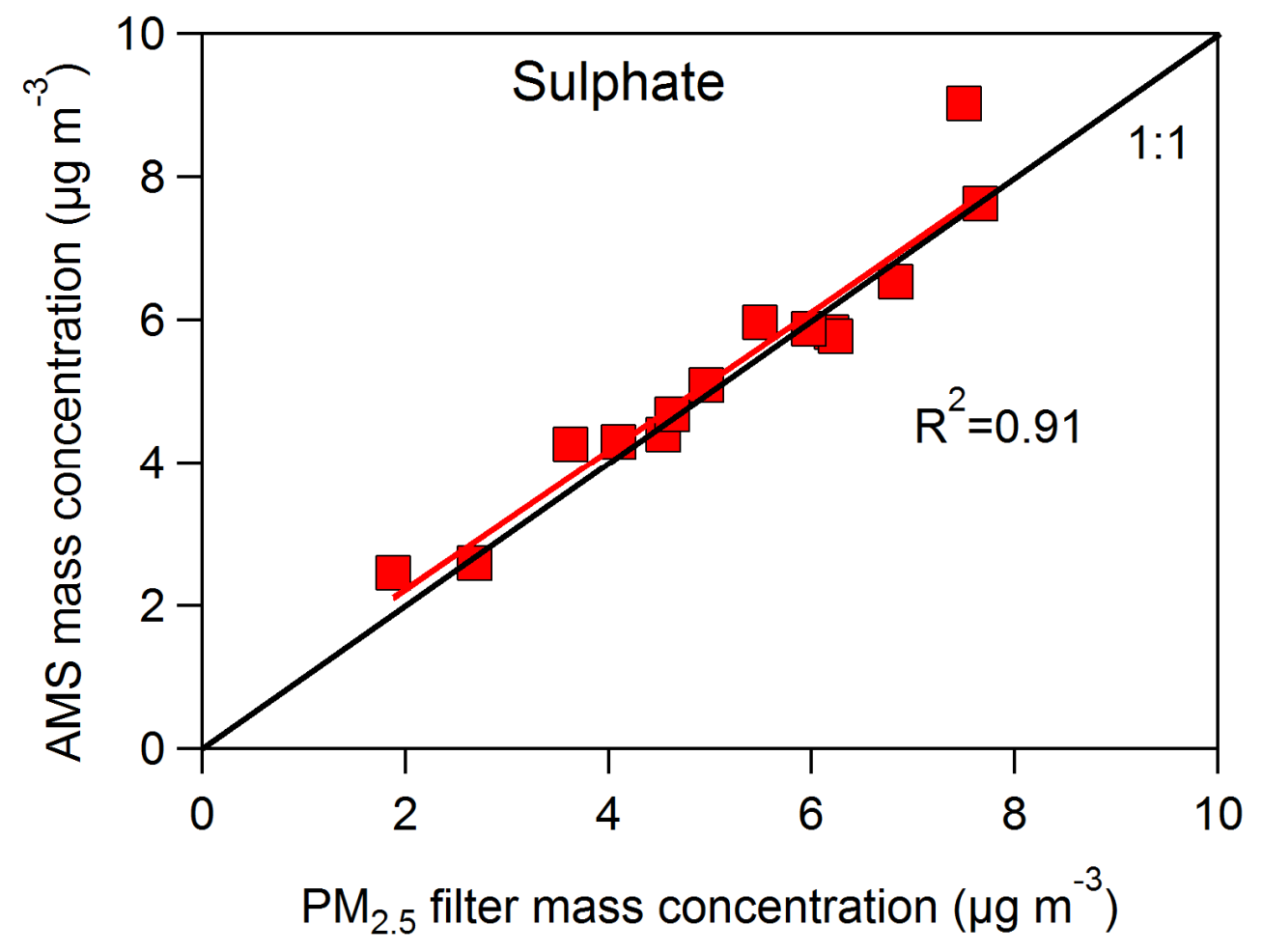

Figure S8. Comparison between the $\mathrm{PM}_{1}$ AMS sulphate (with CE applied) and the $\mathrm{PM}_{2.5}$ filters sulphate for Athens. A high correlation was found $\left(\mathrm{R}^{2}=0.91\right.$, slope $=0.98$, intercept=0.23), implying that most of the $\mathrm{PM}_{2.5}$ sulphate was in the submicrometer range. 


\section{Diurnal profiles of $\mathrm{OA}$ and $\mathrm{BC}$}

The OA average diurnal profile in both cities exhibited three peaks (Figure S9a and S9b). Two of them were associated with primary sources as the BC increased the same time as well.
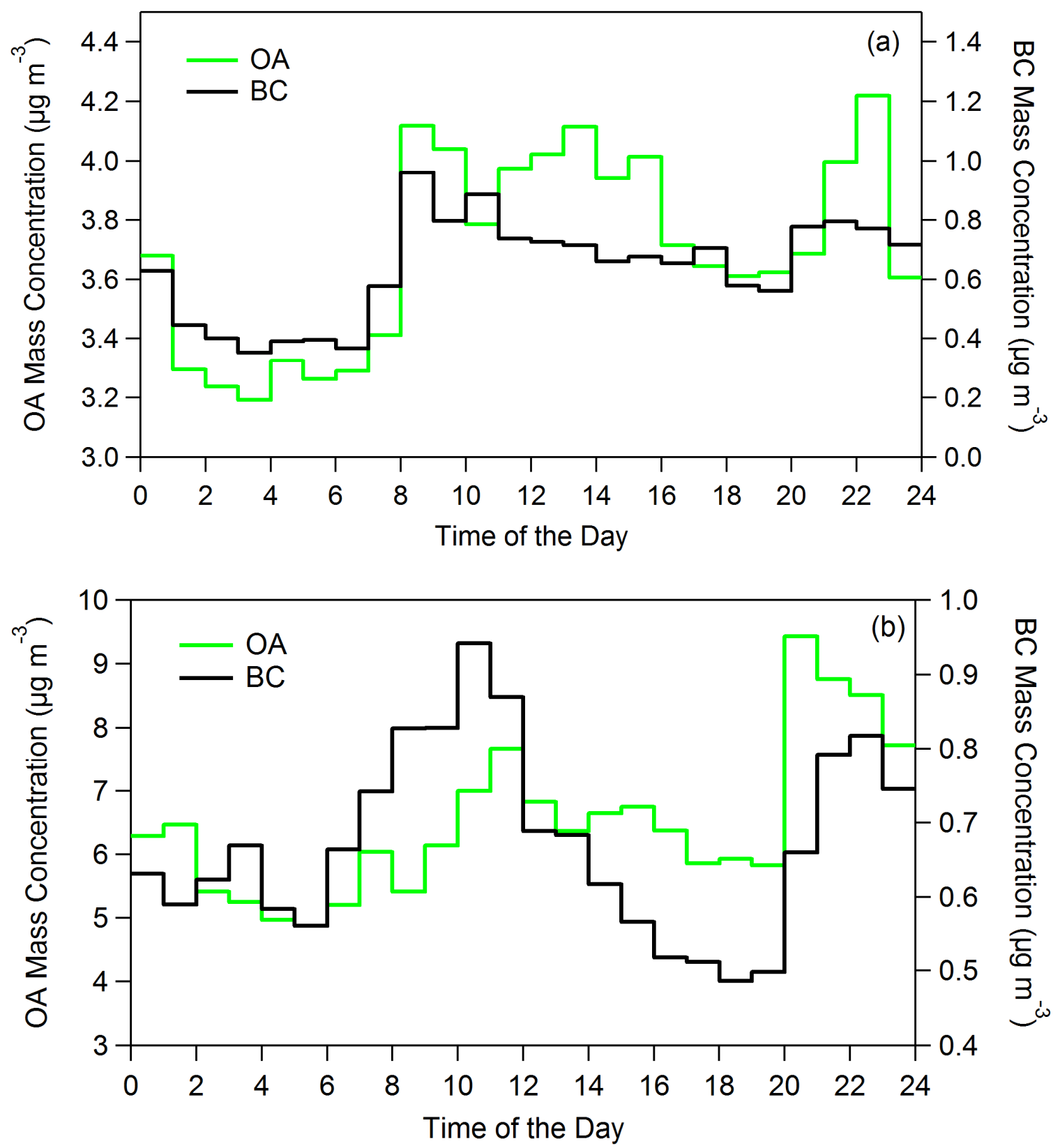

Figure S9. Diurnal profiles of OA and BC: (a) for Patras and (b) for Athens. 


\section{Fractions of $m / z, 44$ and 57}

Figure S10 depicts the times series of $f_{44}$ and $f_{57}$ for Patras and Athens.
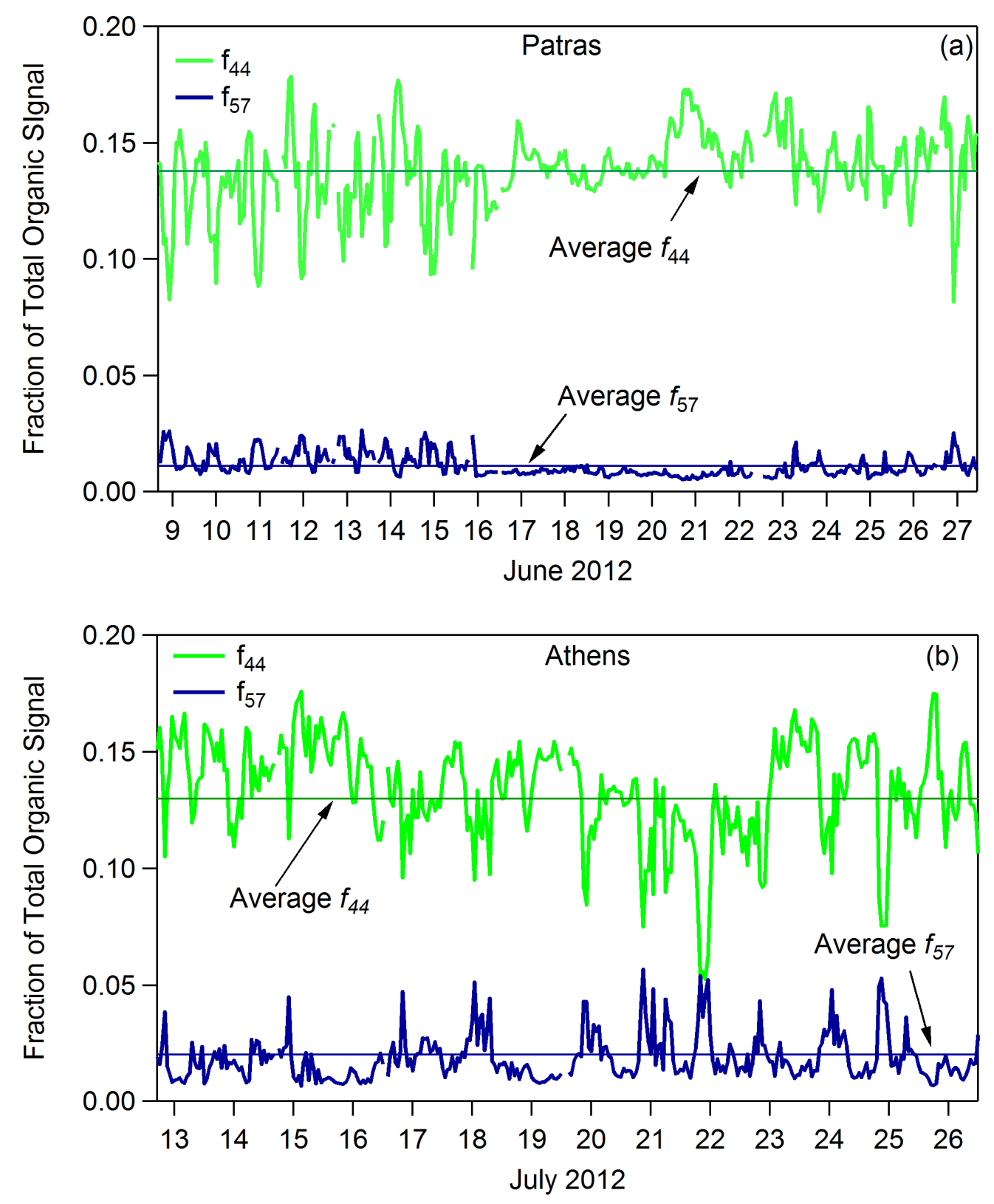

Figure S10. $f_{44}$ and $f_{57}$ time series: (a) For Patras the average $f_{44}$ and $f_{57}$ were 0.14 and 0.01 respectively; (b) For in Athens the $f_{44}$ and $f_{57}$ were on average 0.13 and 0.02 respectively. 


\section{Organic mass concentration from AMS and filters}

The $\mathrm{PM}_{1}$ AMS and $\mathrm{PM}_{2.5}$ filter OA comparison is shown in Figure S11. For Athens, AMS slightly overestimated the organic concentration however this is in the range of the CE uncertainty estimation.
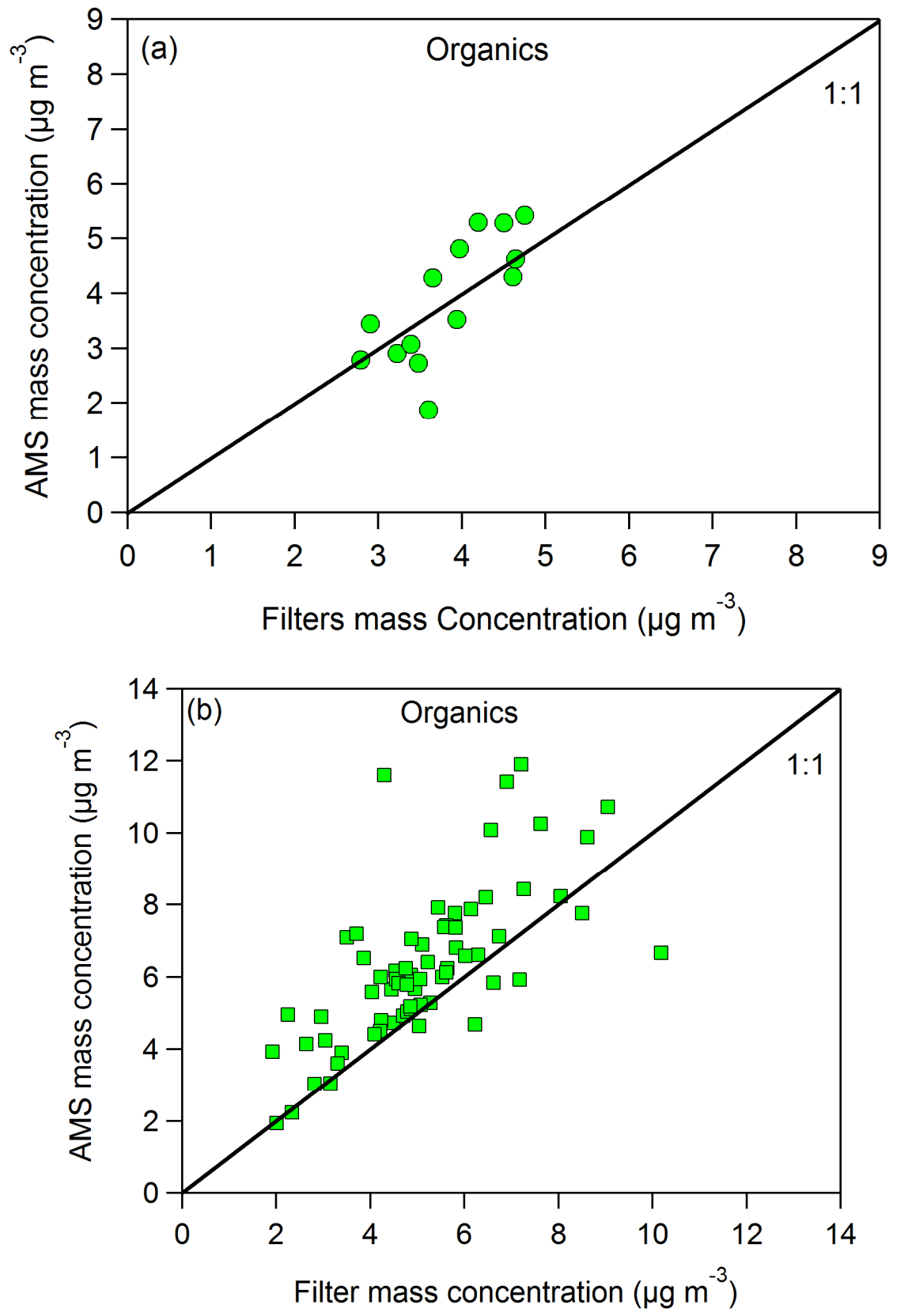

Figure S11. Comparison of the organic mass concentration between the $\mathrm{PM}_{1}$ AMS (after the $\mathrm{CE}$ correction) and the $\mathrm{PM}_{2.5}$ filters measurements, after applying the OM:OC ratio from AMS high resolution data for: (a) Patras and (b) Athens. 


\section{Estimation of organic nitrate fraction}

The organic nitrate contribution was estimated using Farmer et al. (2010) analysis. Figures S12 illustrates the organic nitrate fraction of the measured nitrate in both campaigns.
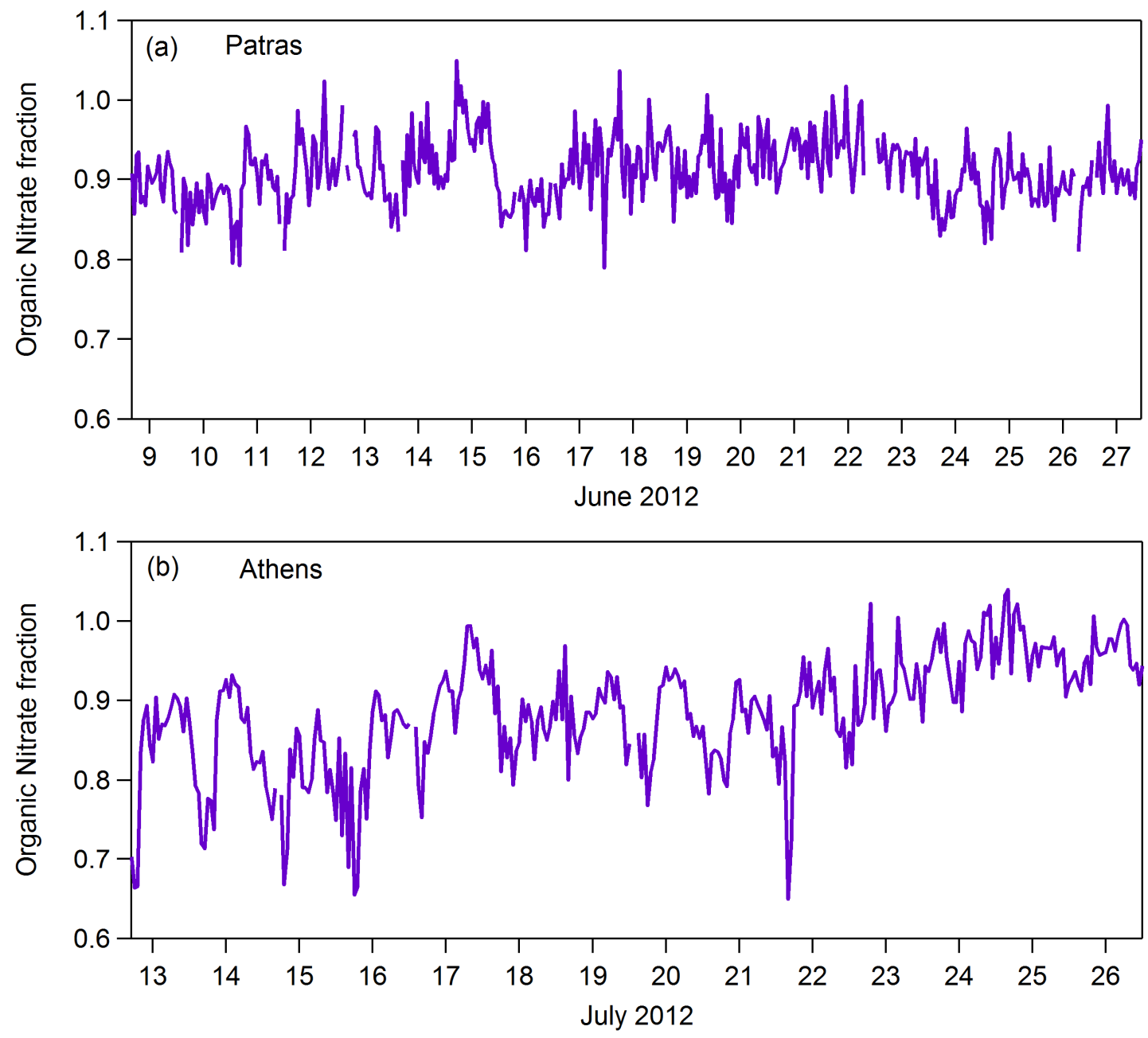

Figure S12. Organic nitrate fraction times series in (a) Patras and (b) Athens. In both cities the average organic nitrate was around $90 \%$ of the total nitrate. 


\section{PMF analysis}

Both PET (Ulbrich et al., 2009) and ME-2 (Lanz et al., 2008; Canonaco et al., 2013) tools were used for the PMF factors determination using the HR organic mass spectra. The selection of the solution depended on the characteristics of the mass spectra and on the correlations of the factor time series with specific tracers.

A. Patras. The model residuals using PET for 1 to 5 factors solution are shown in Figures S13 and S14. Moving from 1 to 2 and from 2 to 3 factors the reduction in the residuals is important. The 4 factor residuals are slightly lower especially for 16 and 25 June 2012 in comparison with the 3 factorial residuals, so the 4 factor choice would seem more appropriate, since the 4 and 5 factor residuals do not have notable difference each other. The $\mathrm{Q} / \mathrm{Q}_{\text {expected }}$ versus the number of the factors is illustrated in Figure $\mathrm{S} 15$.

The solution of the 3 factors (V-OOA, M-OOA and HOA-1) was rejected as $28 \%$ of the $\mathrm{m} / \mathrm{z} 43$ and $27 \%$ of the $\mathrm{m} / \mathrm{z} 55$ of the HOA spectrum was oxygenated (Figure S16), and due to the residuals reason described above.

For the 4 factor solution $\left(f_{\text {peak }}=0\right.$, using ME-2) 17 out of 20 seeds resulted in the factors: HOA-1, b-OOA, M-OOA and V-OOA (Figure S17a). However, the HOA-1 mass spectrum contained oxygenated species at the $m / z 43(22 \%)$ and at $m / z 55(25 \%)$, which is not common for an HOA spectrum (e.g. Sun et al., 2011; Mohr et al., 2012). 3 out of 20 seeds gave the factors: HOA-1, HOA-2, M-OOA and V-OOA (Figure S17b). In this case the $f_{44}$ of the HOA-1 is higher than the $f_{43}$ and the oxygenated part of $m / z 43$ and 55 are 30 and $15 \%$ correspondingly. For the reasons above we rejected the 4 factor solution.

Moving to 5 factors $\left(f_{\text {peak }}=0\right.$, using ME-2) the factors extracted were: HOA-1, HOA-2, b-OOA, M-OOA and V-OOA. 12 out of 20 seeds gave again an HOA-1 factor with oxygenate species contribution at $\mathrm{m} / \mathrm{z}$ 's 43 and 55 (22 and 10\%) (Figure S18a). 8 out of 20 seeds resulted in an HOA-1 less oxygenated compared to the previous cases $(13 \%$ in $\mathrm{m} / \mathrm{z} 43$ and $7 \%$ at $\mathrm{m} / \mathrm{z} 55$ ) (Figure S18b). The OOA (V-OOA, M-OOA and b-OOA) and primary OA (HOA-1 and HOA-2) fractions of the 4 factor solution (76\% and 24\% correspondingly) do not change significantly compared to those of the 5 factor case $(78 \%$ and $22 \%$ accordingly). Thus we believe that this is a more appropriate solution for Patras. 
We also examined the different rotational solutions for the 5 factor case (Figure $\mathrm{S} 19)$. According to ME-2 all the solutions for all the factors were very stable for $f_{\text {peak }}-1$ to 1 , however giving a higher $f_{44}$ compared to $f_{43}$ for HOA-2 which mostly has primary signatures and its diurnal profile resembles cooking emissions (these solutions are the same solutions derived by $12 / 20$ seeds for $f_{\text {peak }}=0$ ). For $f_{\text {peaks }}=-0.4$ and $0.2, f_{44}$ became lower than $f_{43}$ (this case is the same solution that $8 / 12$ seeds gave for $f_{\text {peak }}=0$ ). We selected this solution because since HOA-2 is a primary source $f_{44}$ should be lower than $f_{43}$. Using PET M-OOA and HOA-1 did not change significantly in the same $f_{\text {peak }}$ range. However, V-OOA, b-OOA and HOA-2 changed for $f_{\text {peaks }} \geq 0.6,0.4$ and 0.8 correspondingly. In the stable $f_{\text {peak }}$ range -1 to 0.2 the solutions were alike each other and resembled the ME-2 HOA-2 solution for $f_{\text {peaks }}=-0.4$ and 0.2 . Among these alike solutions we chose $f_{\text {peak }}=0$ which gave the minimum value of $\mathrm{Q} / \mathrm{Q}_{\text {expected }}$ using PET. Q/Q expected for ME-2 and PET are illustrated in Figure S20.

In the case of 6 factors the M-OOA is split in 2 parts with similar $f_{44}(0.16$ in M1OOA and 0.15 in M2-OOA) (Figure S21).

B. Athens. For Athens measurements a 4-factor solution was selected. Figure S25 and S26 illustrates the model residuals for 1 to 5 factors solution obtained by PET. From 1 to 2 and from 2 to 3 factors there is significant difference in the residuals, while between 4 and 5 factors the reduction is very low. The $\mathrm{Q} / \mathrm{Q}_{\text {expected }}$ versus the number of the factors is illustrated in Figure S27. The Q/Q ${ }_{\text {expected }}$ for $f_{\text {peak }}=-1$ to 1 for ME-2 and PET are depicted in Figure S28.The factor time series and corresponding mass spectra from PET and ME-2 are almost identical each other (Figure S29).

We checked the mass spectra behavior in the $f_{\text {peak }}$ range - 1 to 1 (Figure S30) investigating $f_{44}$ versus $f_{43}$. The 4 solutions obtained by ME-2 were quite stable (Figure 3a). The corresponding 4 solutions derived by PET were again stable expect for the MOOA which was different for $f_{\text {peaks }} \geq 0.6$. Among the stable solutions we selected the $f_{\text {peak }}=0$, as the $\mathrm{Q} / \mathrm{Q}_{\text {expected }}$ was lower using PET, while $\mathrm{Q} / \mathrm{Q}_{\text {expected }}$ obtained from $\mathrm{ME}-2$ which for the fpeak range -1 to 1 was practically the same (Figure S29).

The 3 factor solution is shown in Figure S31, where the 3 factors are HOA-1, HOA-2 and OOA. Again the time series and the mass spectra of the factors obtained by 
PET and ME-2 are identical (not shown). We reject the 3 factorial choice due to the residuals characteristics described above and as most of the recent studies refer that during the summer the OOA is usually split in a more oxygenated and a less oxygenated part (e.g. Aiken et al., 2009; Docherty et al., 2011; Sun et al., 2011; Mohr et al., 2012; Crippa et al., 2013).

The 5 factor selection was investigated as well. Performing PMF analysis with ME-2 we obtained 2 slightly different cases: 11 out of the 20 seeds split the M-OOA into 2 parts, which both of them have similar $f_{44}$ contribution ( 0.14 for M1-OOA and 0.15 for M2-OOA, Figure S32a). Additionally the diurnal profile of M1-OOA is similar to the HOA-2 profile, and this a second reason we reject this combination (Figure S32b). This is the solution that from PET for $f_{\text {peak }}=0$. For 9 out of 20 seeds the OOA is divided into 3 OOA factors V-OOA, M1-OOA and M2-OOA with $f_{44}: 0.20,0.17$ and 0.14 correspondingly (Figure S33a). In this case the M2-OOA profile resembles the HOA-2 profile, which implies that this factor also include part of the HOA-2 (Figure S33b). 

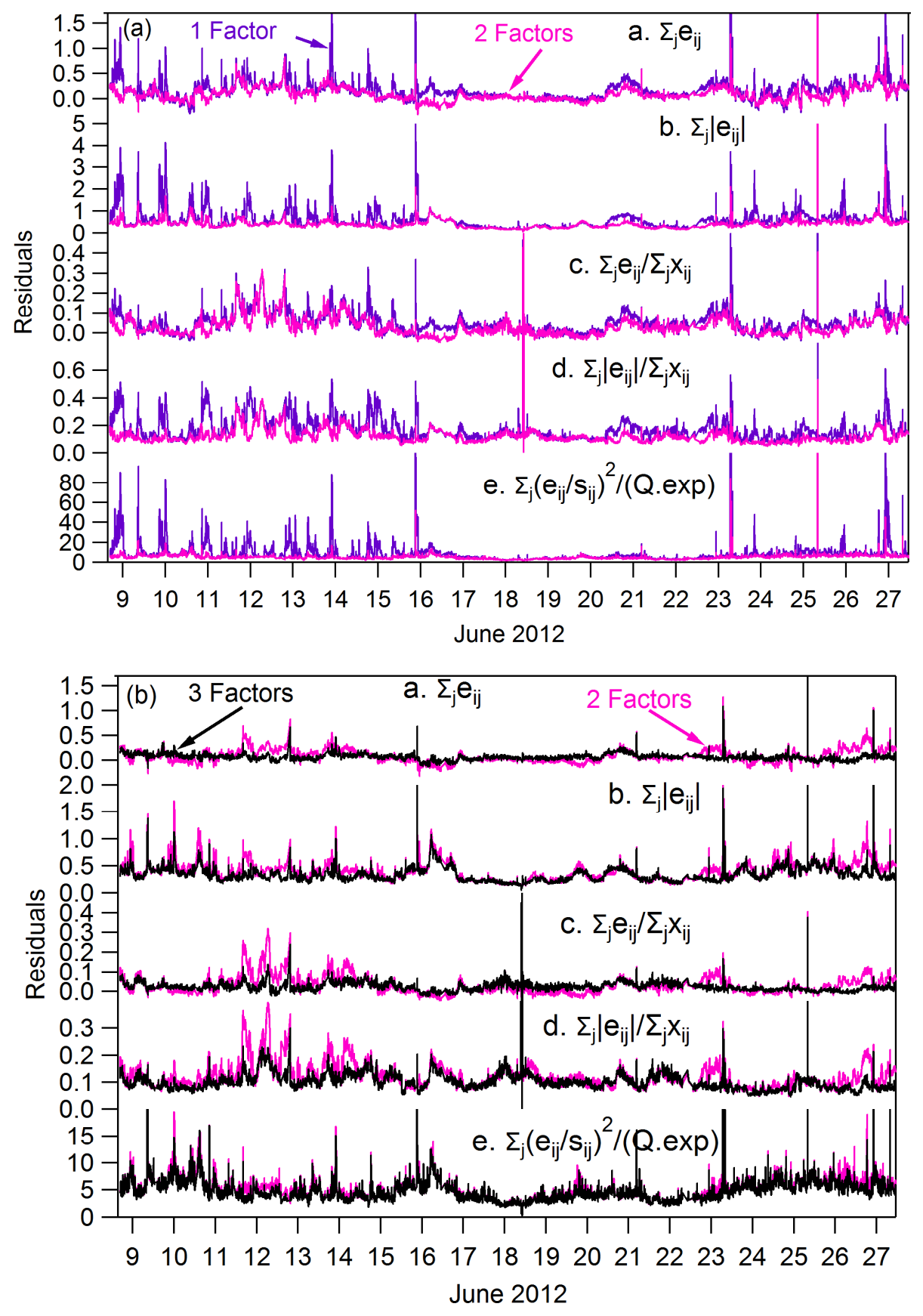

Figure S13. Model residuals $\mathbf{E}=\mathbf{X}-\mathbf{G F}$ calculated using the PMF evaluation tool, PET (Ulbrich et al., 2009) for Patras. Comparison between: (a) 1-factor (purple lines) and 2 factor (pink lines) PMF solution and (b) 2-factor (pink lines) to 3-factor (black lines) PMF solution. The residuals decreased importantly from 1 to 2 factors and from 2 to 3 factors. 

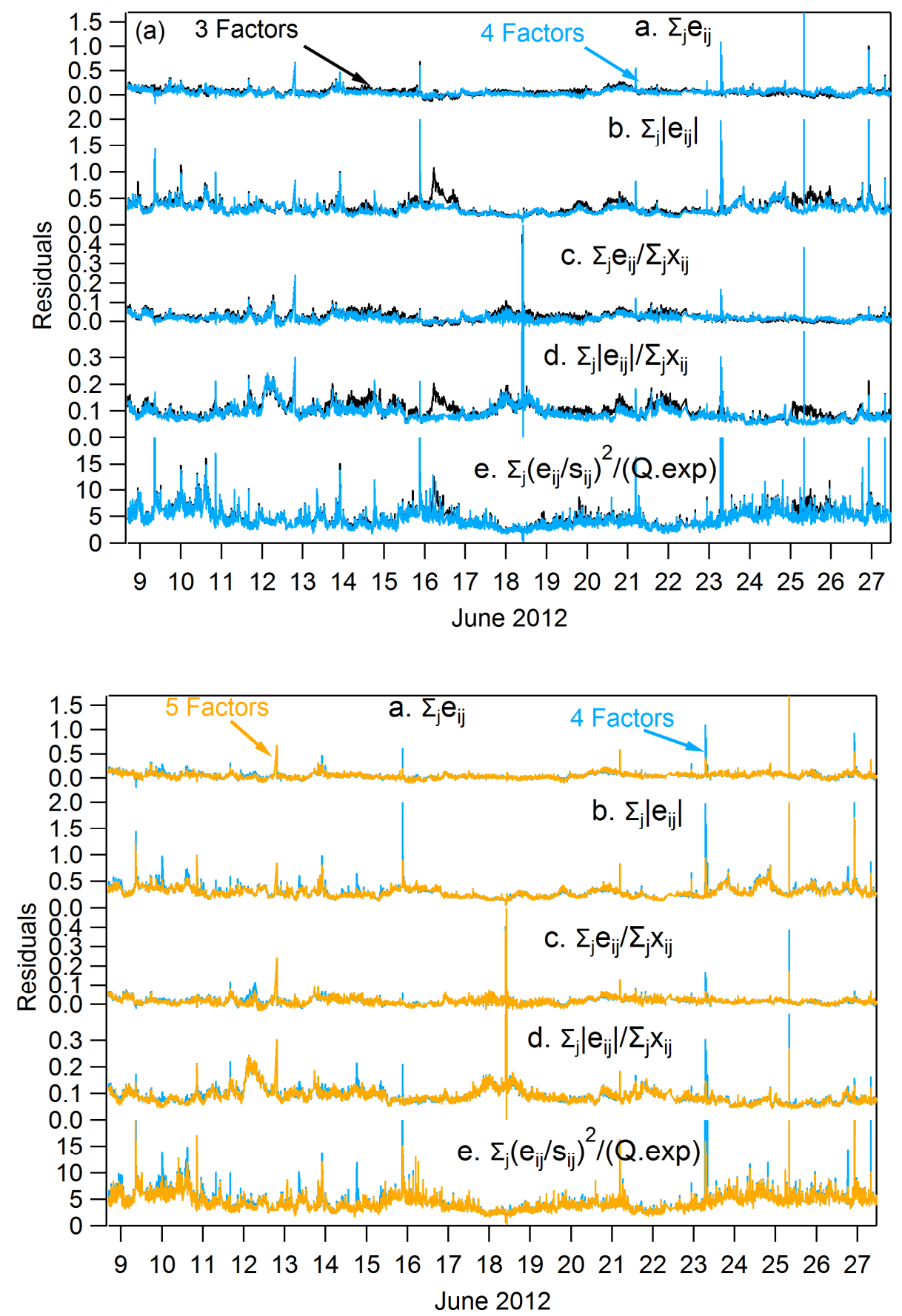

Figure S14. Model residuals $\mathbf{E}=\mathbf{X}-\mathbf{G F}$ calculated using the PMF evaluation tool, PET (Ulbrich et al., 2009) for Patras. Comparison between: (a) 3-factor (black lines) and 4factor (light blue lines) PMF solutions and (b) 4-factor (light blue lines) and 5-factor (orange lines) PMF solutions. The residuals decreased slightly from 3 to 4 factors for the $16^{\text {th }}$ and $25^{\text {th }}$ June 2012. Between the 4 and 5 factor solution residuals there was only very low change. 


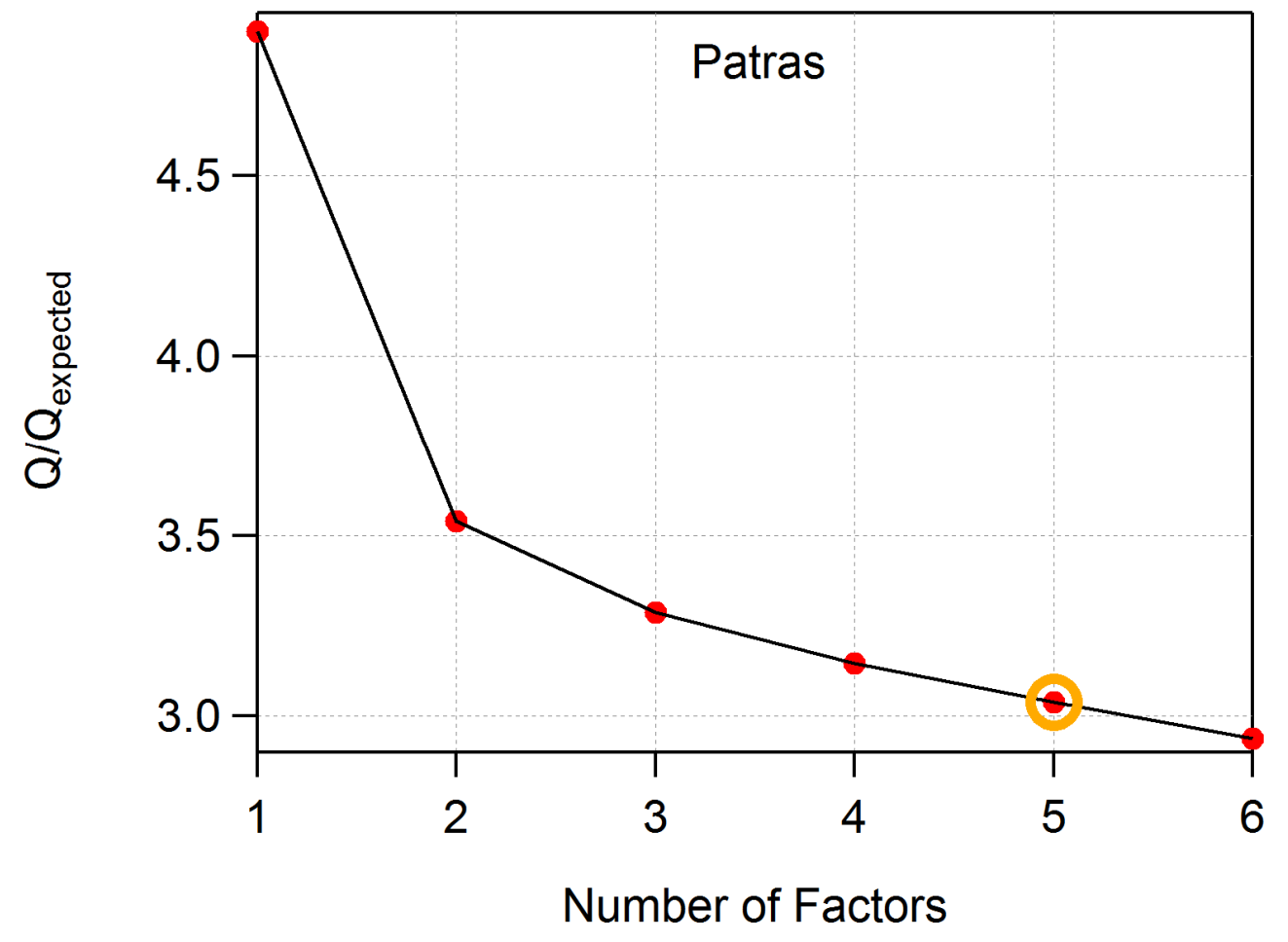

Figure S15. Q/Q expected versus the number of the factors for Patras. 


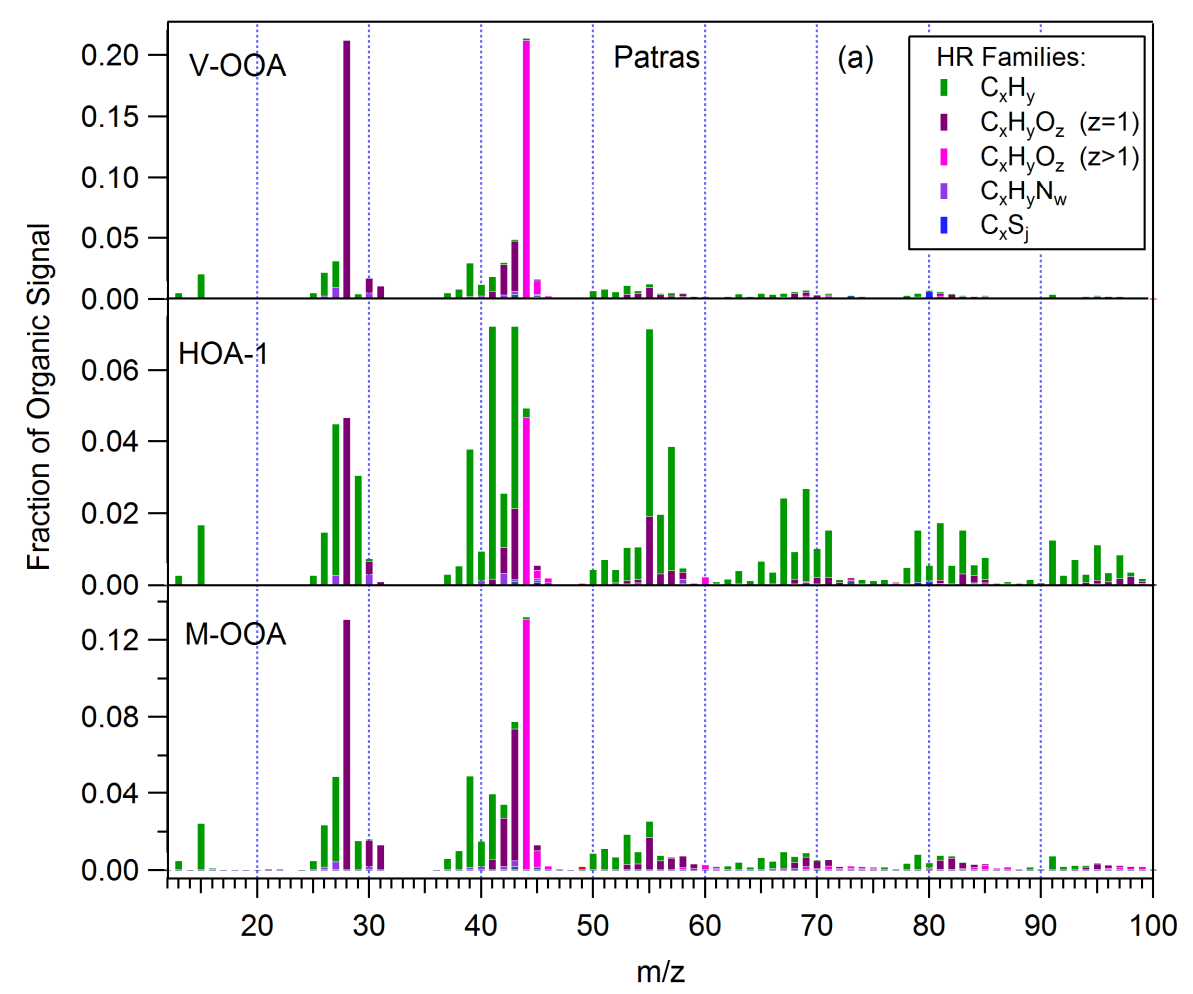

Figure S16. The mass spectra for the 3-factor solution which resulted in an oxygenated HOA-1 spectrum for Patras. 

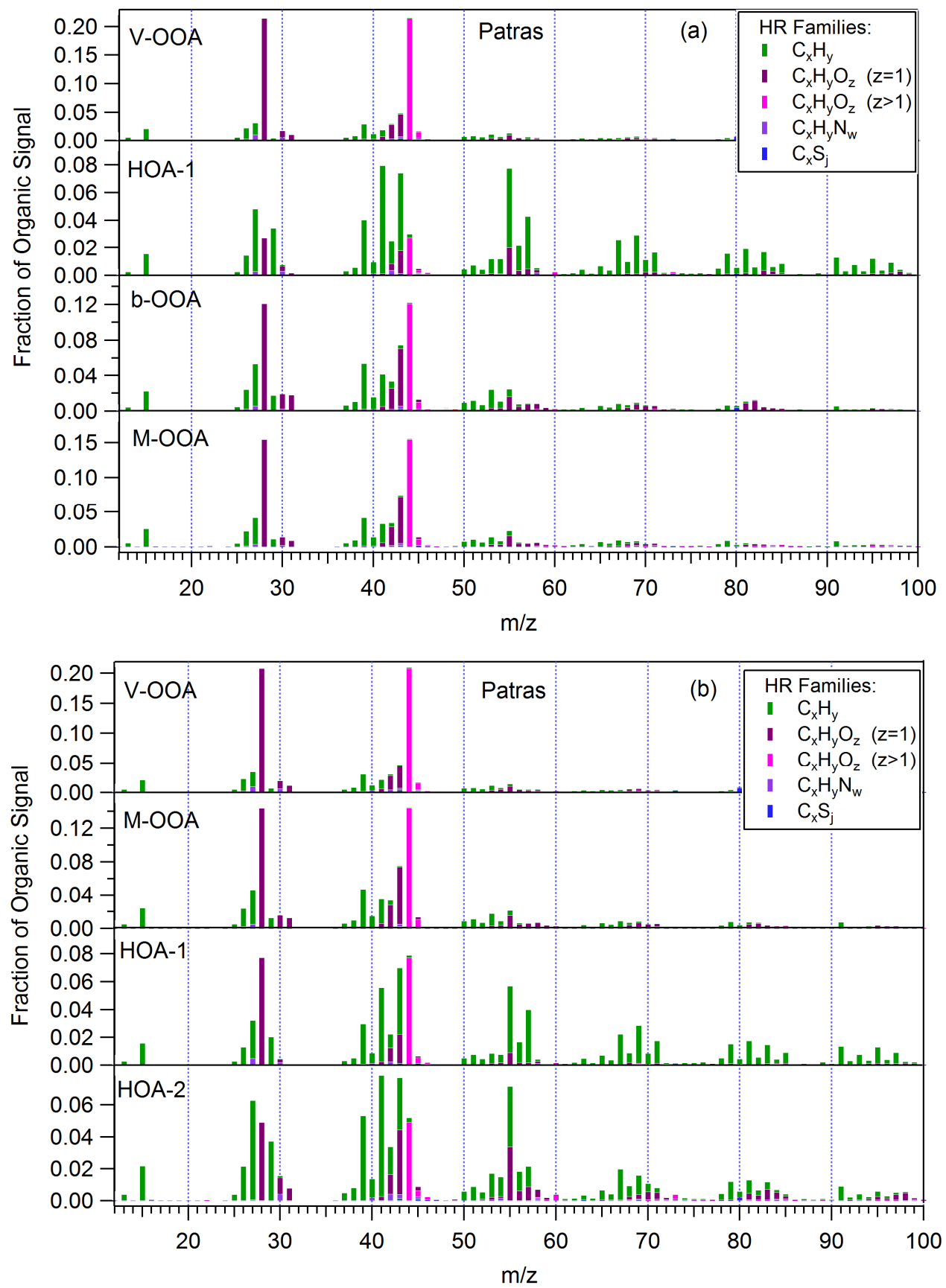

Figure S17. The 4-factor solution mass spectra (Patras) for: (a) the more stable case and (b) the less stable case. In both cases the HOA spectrum contains oxygenated species at $m / z$ 's 43 and 55, while in the second case HOA-1 has a high $m / z 44$ contribution. 

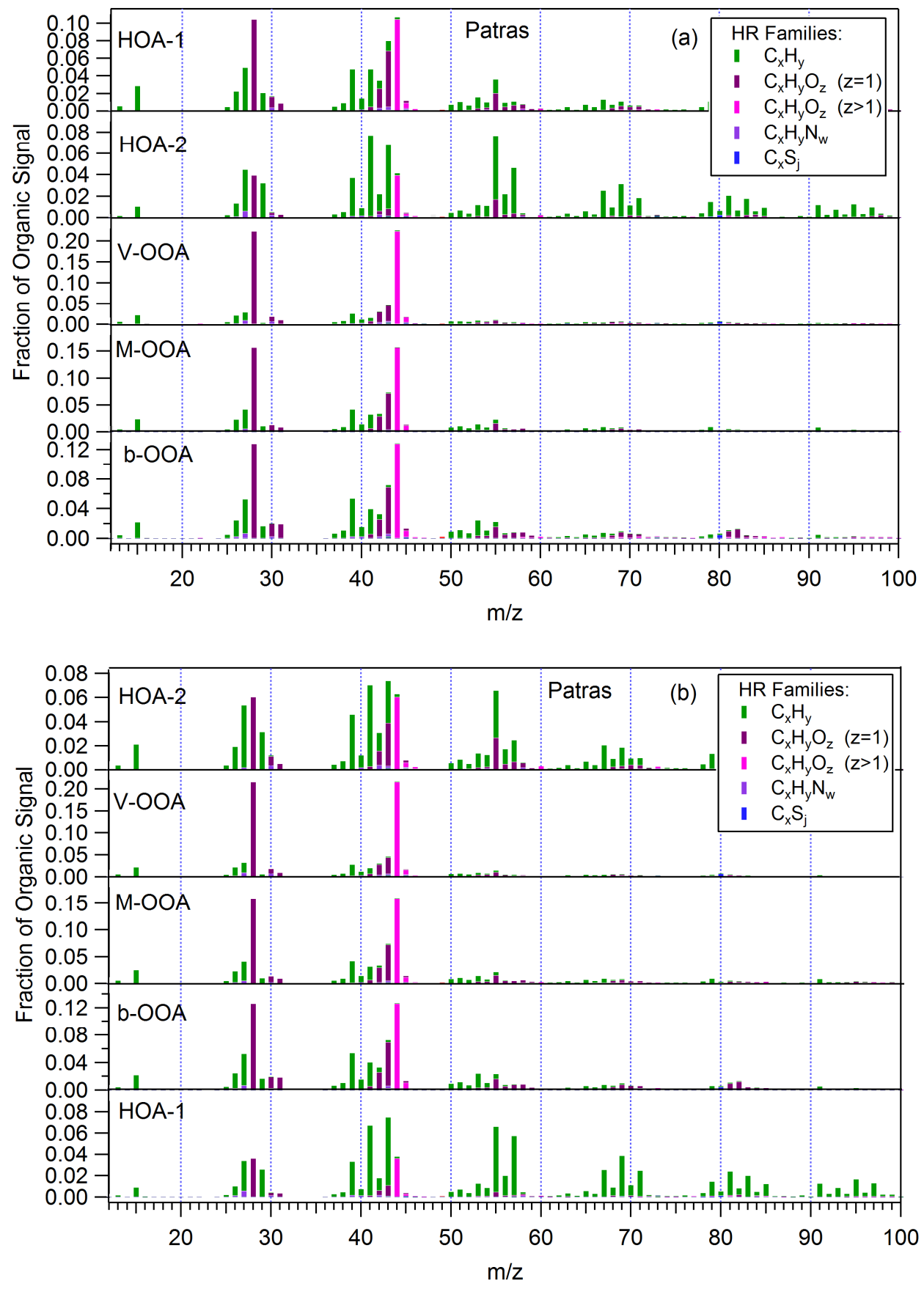

Figure S18. The 5-factor solution mass spectra (Patras) for: (a) 12 out of 20 seeds and (b) 8 out of 20 seeds. The second option is more appropriate since the HOA-1 mass spectra contains less oxygenated compounds at $m / z 43$ and 55 compared with the previous case. 

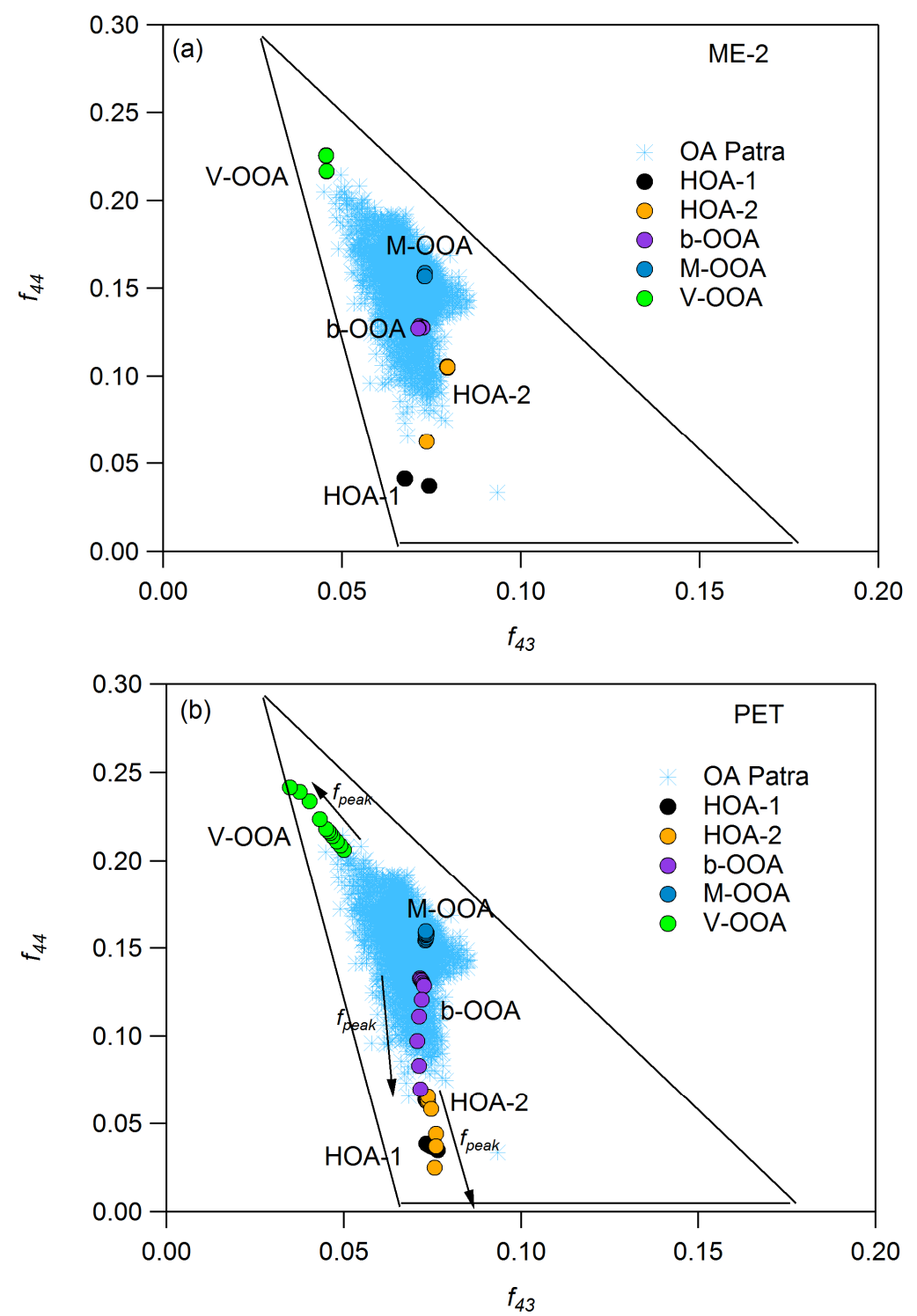

Figure S19. $f_{44}$ versus $f_{43}$ for the 5 -factor solution found in Patras for $f_{\text {peaks }}-1$ to 1 using (a) ME-2 and (b) PET software. 

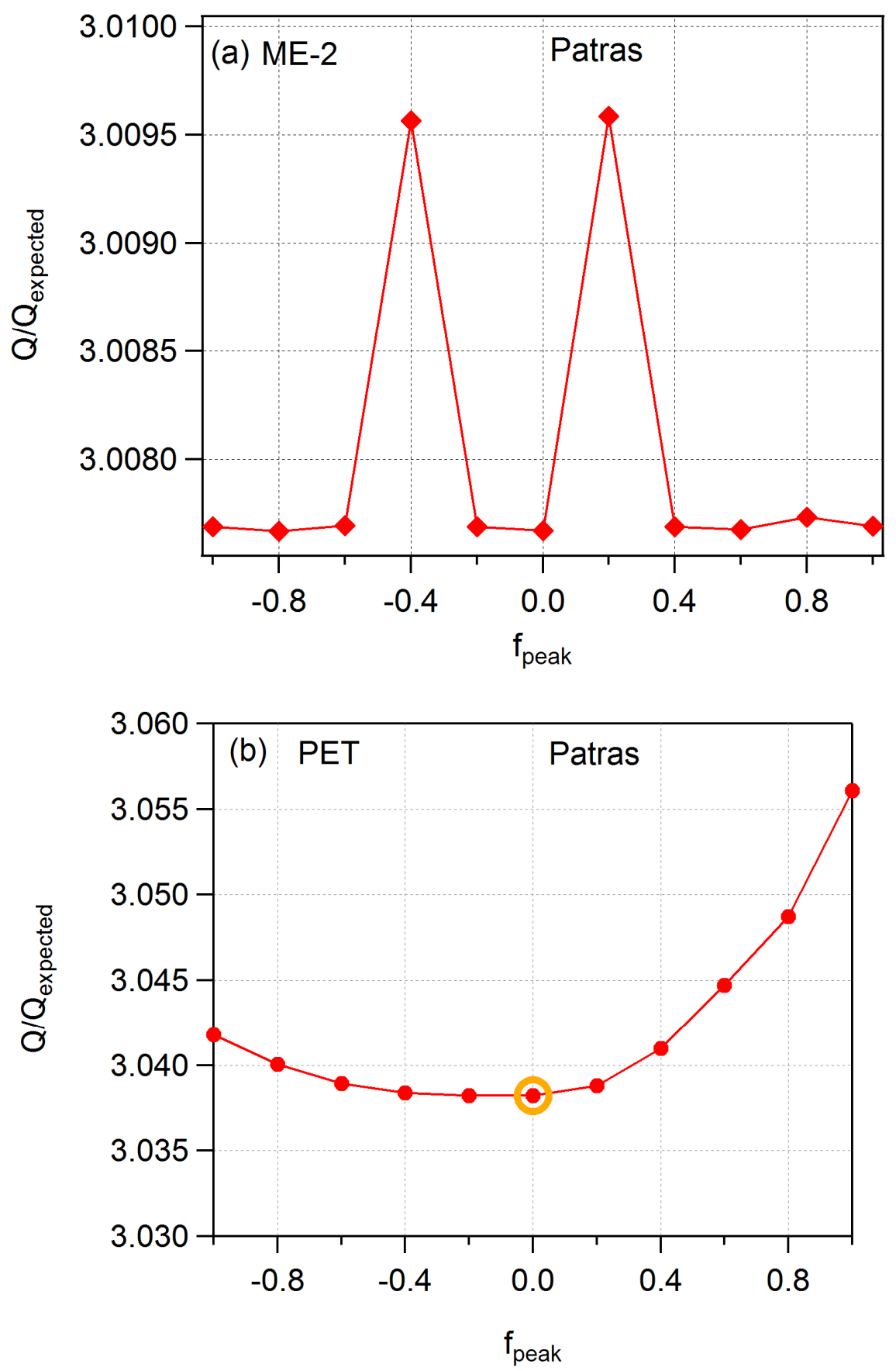

Figure S20. Q/Q expected for $f_{\text {peaks }}-1$ to 1 for a 5 factor solution for Patras using: (a) ME-2 and (b) PET. For ME-2 all the solutions except for $f_{\text {peaks }}=-0.4$ and 0.2 correspond to a very similar $\mathrm{Q} / \mathrm{Q}_{\text {expected. }}$ Using PET there is a stable area between $\mathrm{f}_{\text {peaks }}-0.4$ and 0 with lower $\mathrm{Q} / \mathrm{Q}_{\text {expected }}$ at $f_{\text {peak }}=0$. 


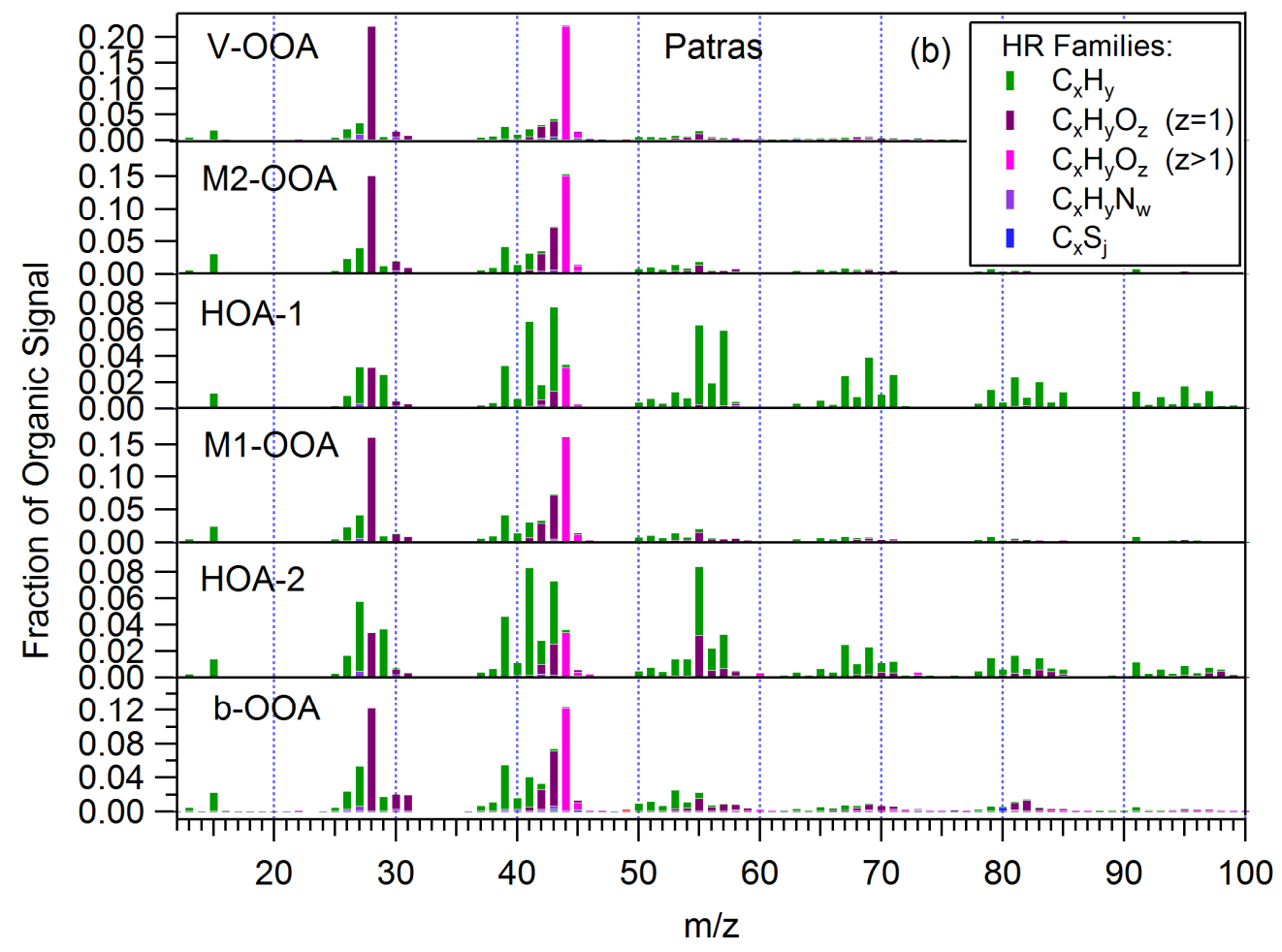

Figure S21. The mass spectra for the 6-factor solution in which the M-OOA is split in 2 factors (Patras). 


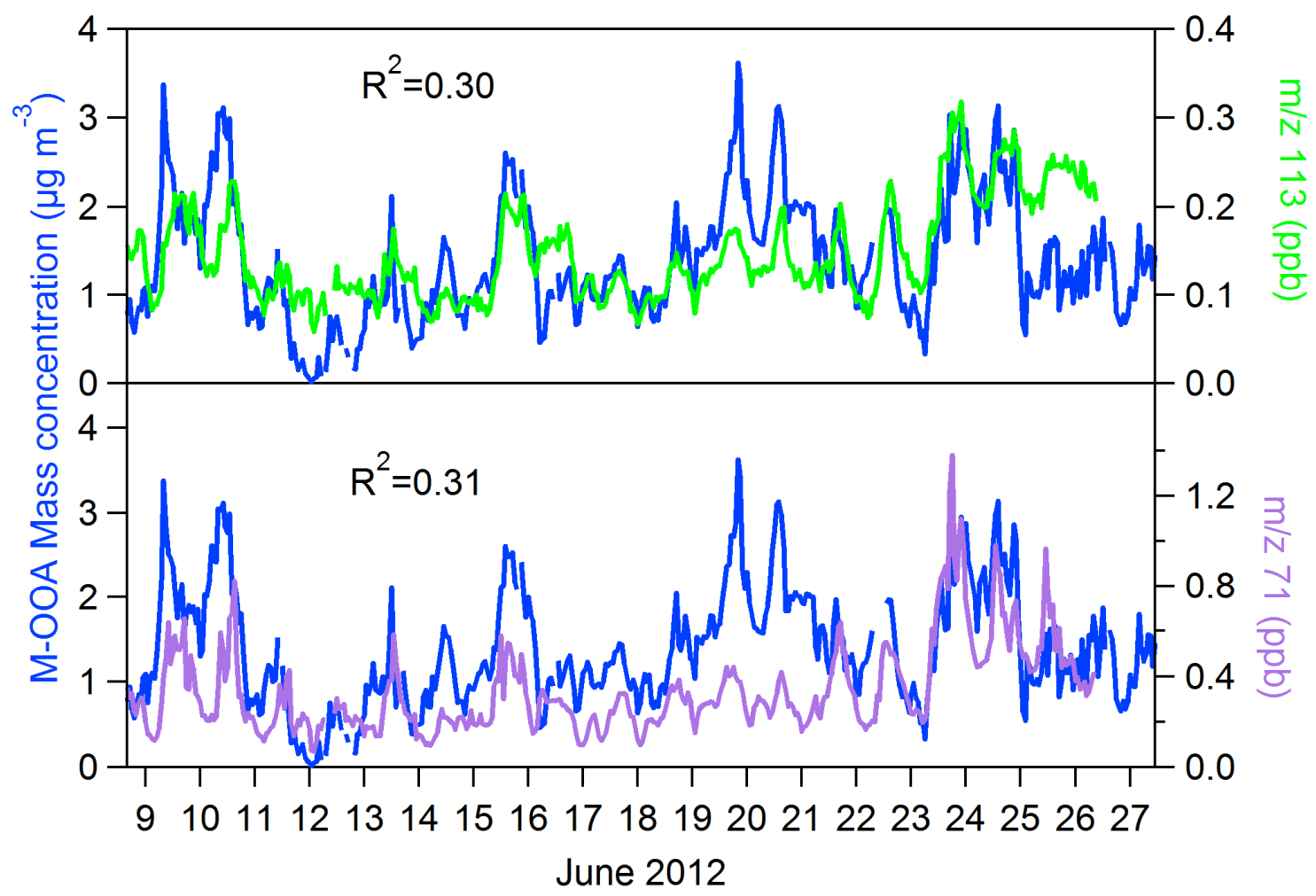

Figure S22. The time series of Patras M-OOA compared to the times series of $\mathrm{m} / \mathrm{z} 113$ (terpene oxidation products) and $m / z 71$ (MVK and MACR). 
NOAA HYSPLIT MODEL

Backward trajectories ending at 0900 UTC 11 Jun 12

GDAS Meteorological Data

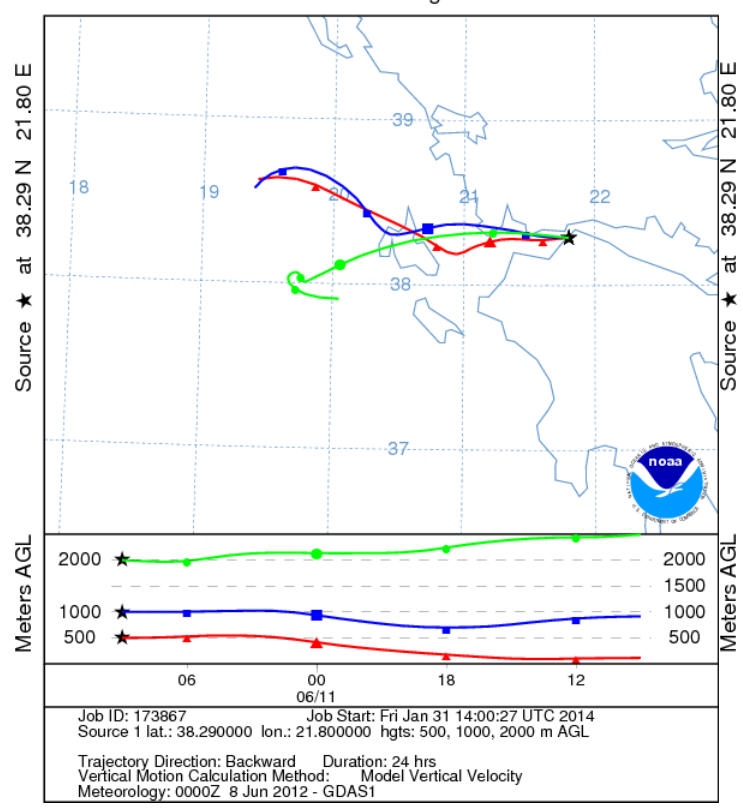

NOAA HYSPLIT MODEL

Backward trajectories ending at 1500 UTC 16 Jun 12

GDAS Meteorological Data

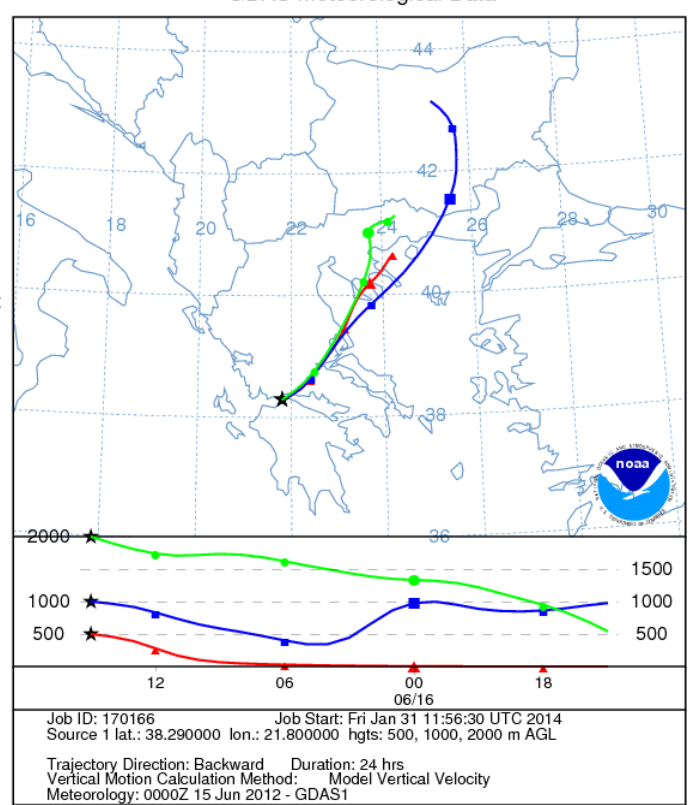

Figure S23. HYSPLIT back trajectories (Draxler and Rolph, 2013) for Patras. When the air originated from the west (above the Ionian Sea) the b-OOA levels were very low, while when the air masses were coming form NE and after have passing though the mountains in Central Greece the b-OOA increased. 


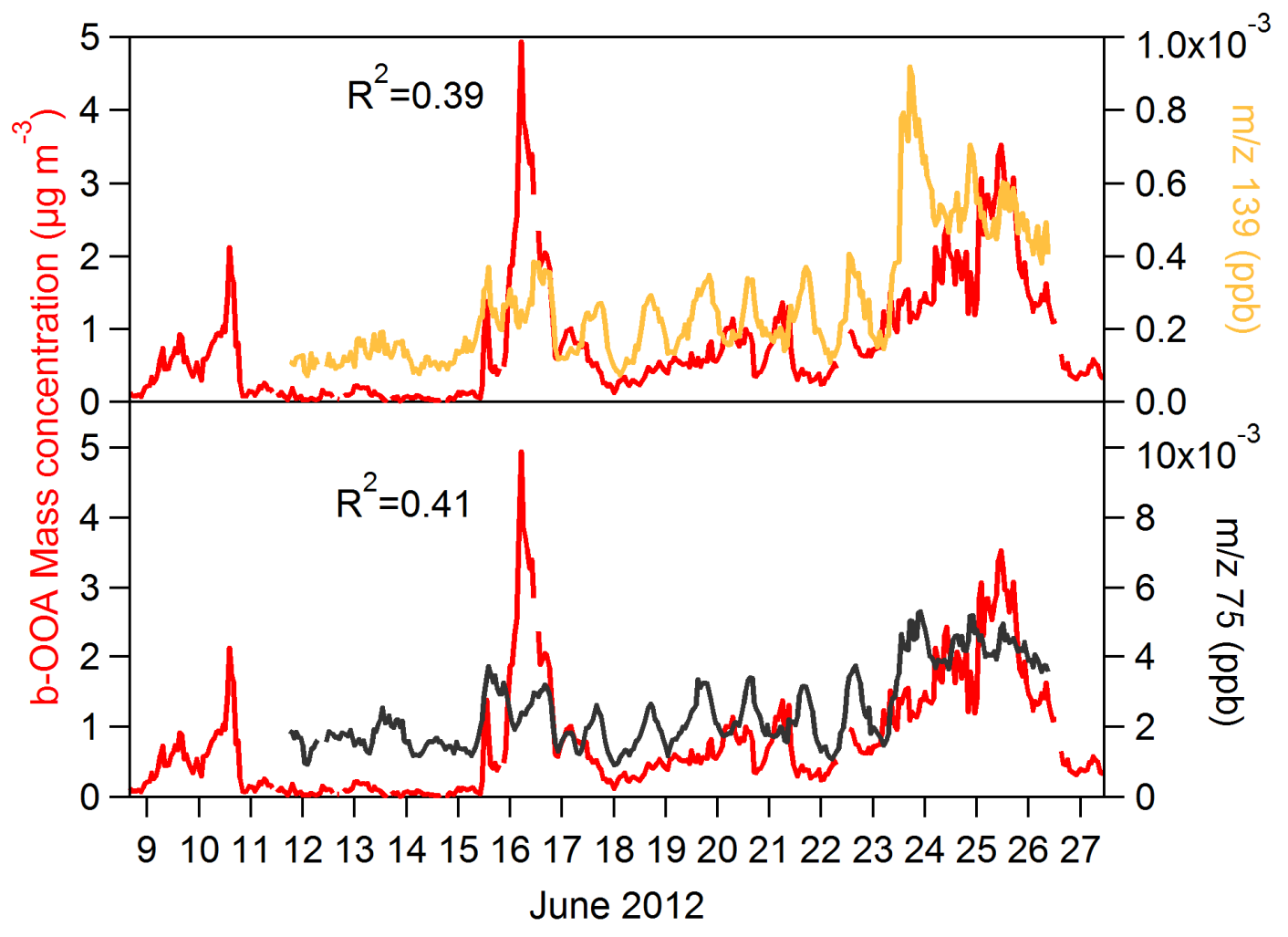

Figure S24. Time series of b-OOA found in Patras in comparison with PTR-MS $\mathrm{m} / \mathrm{z}^{\text {' }} \mathrm{s}$ 139 (nopinone) and 75 (hydroxyl-acetone). 

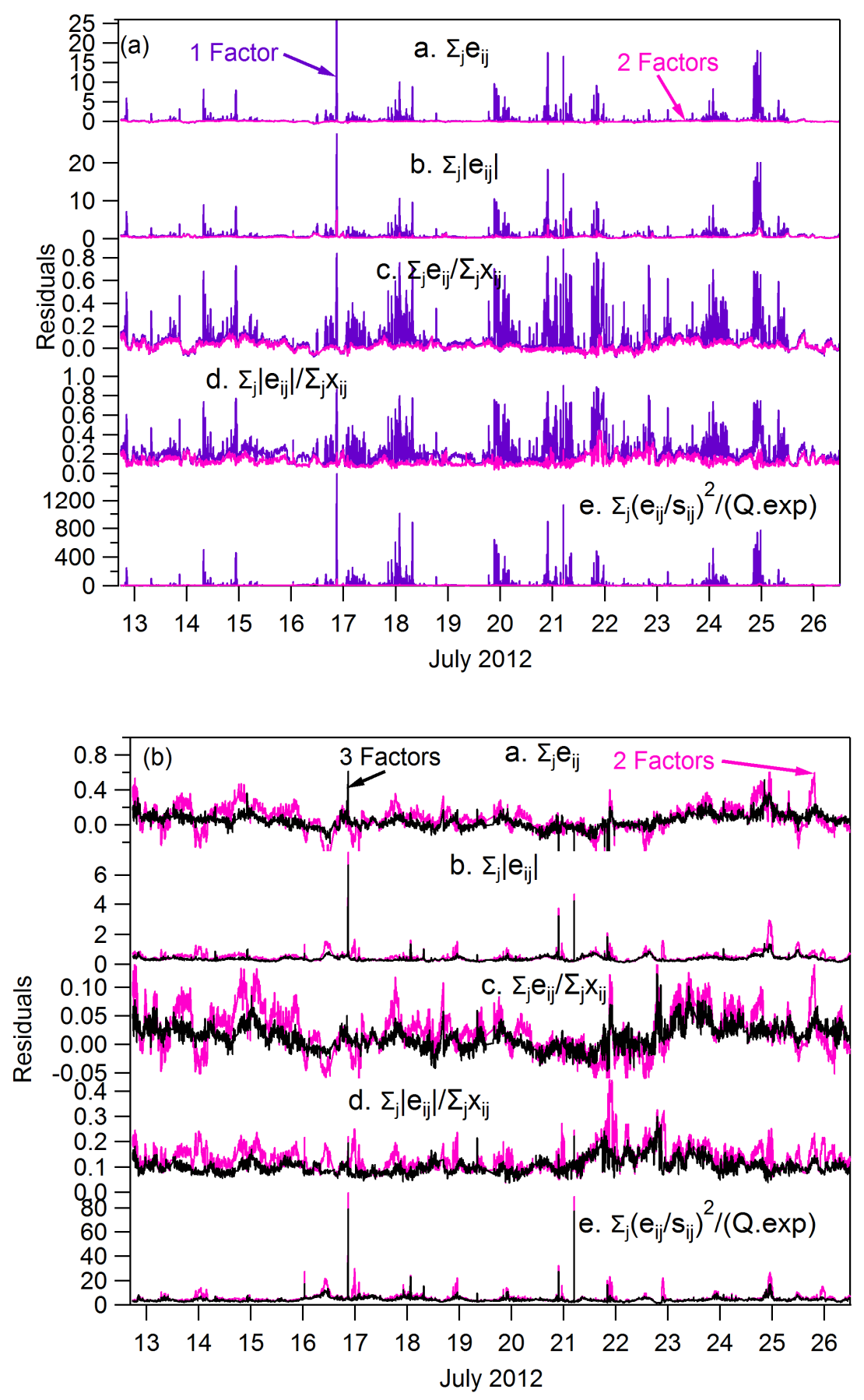

Figure S25. Model residuals $\mathbf{E}=\mathbf{X}-\mathbf{G F}$ calculated using the PMF evaluation tool, PET (Ulbrich et al., 2009) for Athens. Comparison between: (a) 1-factor (purple lines) and 2factor (pink lines) PMF solution and (b) 2-factor (pink lines) to 3-factor (black lines) PMF solution. Moving from 1 to 2 factors and from 2 to 3 factors the residuals decreased significantly. 

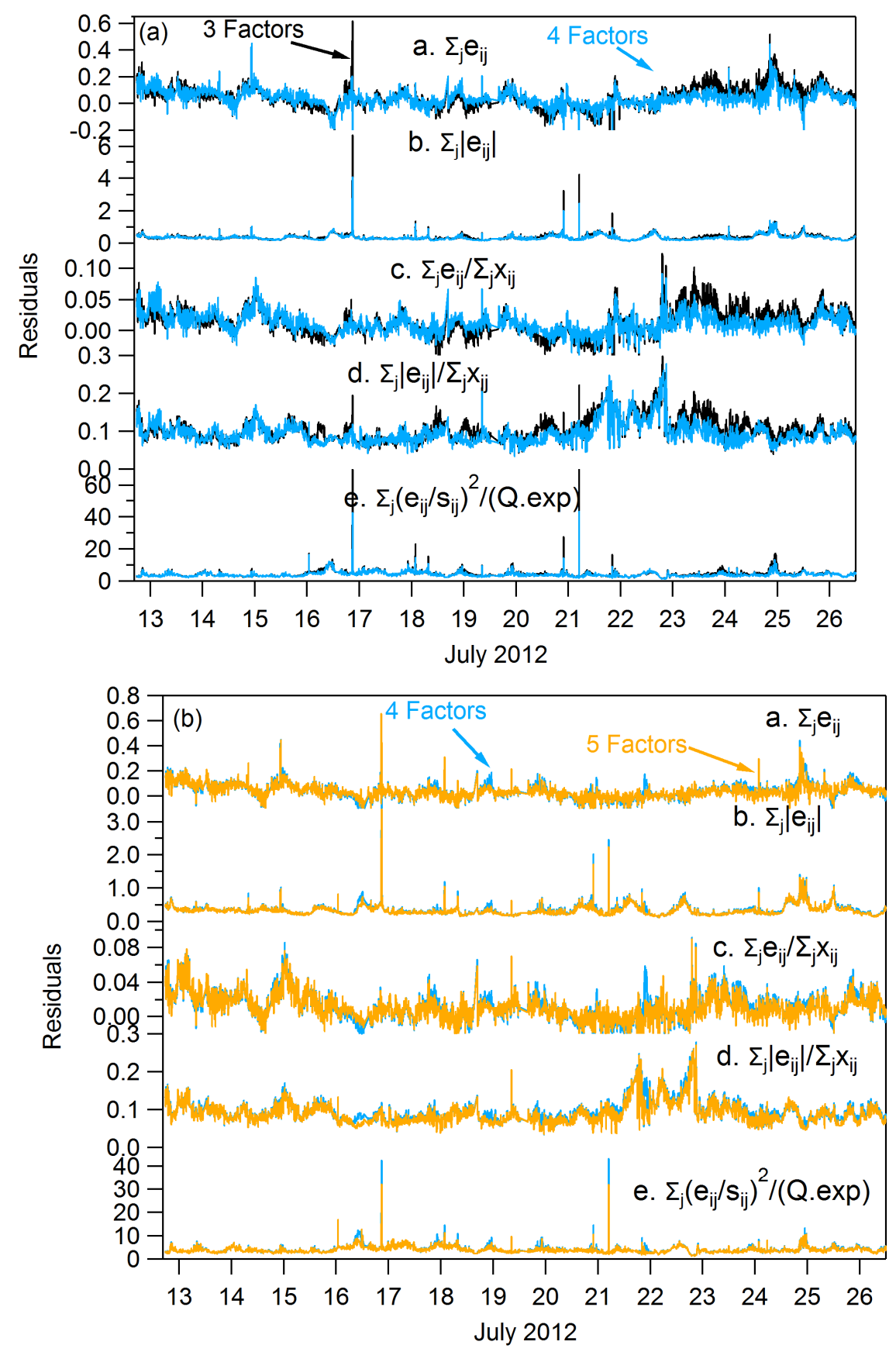

Figure S26. Model residuals $\mathbf{E}=\mathbf{X}-\mathbf{G F}$ calculated using the PMF evaluation tool, PET (Ulbrich et al., 2009) for Athens. Comparison between (a) 3-factor (black lines) and 4factor (light blue lines) PMF solutions and (b) 4-factor (light blue lines) and 5-factor (orange lines) PMF solutions. The 4-factor residuals are slightly lower in comparison with the residuals of the 3 -factor solution. The 4 and 5 factor solution residuals were quite similar. 


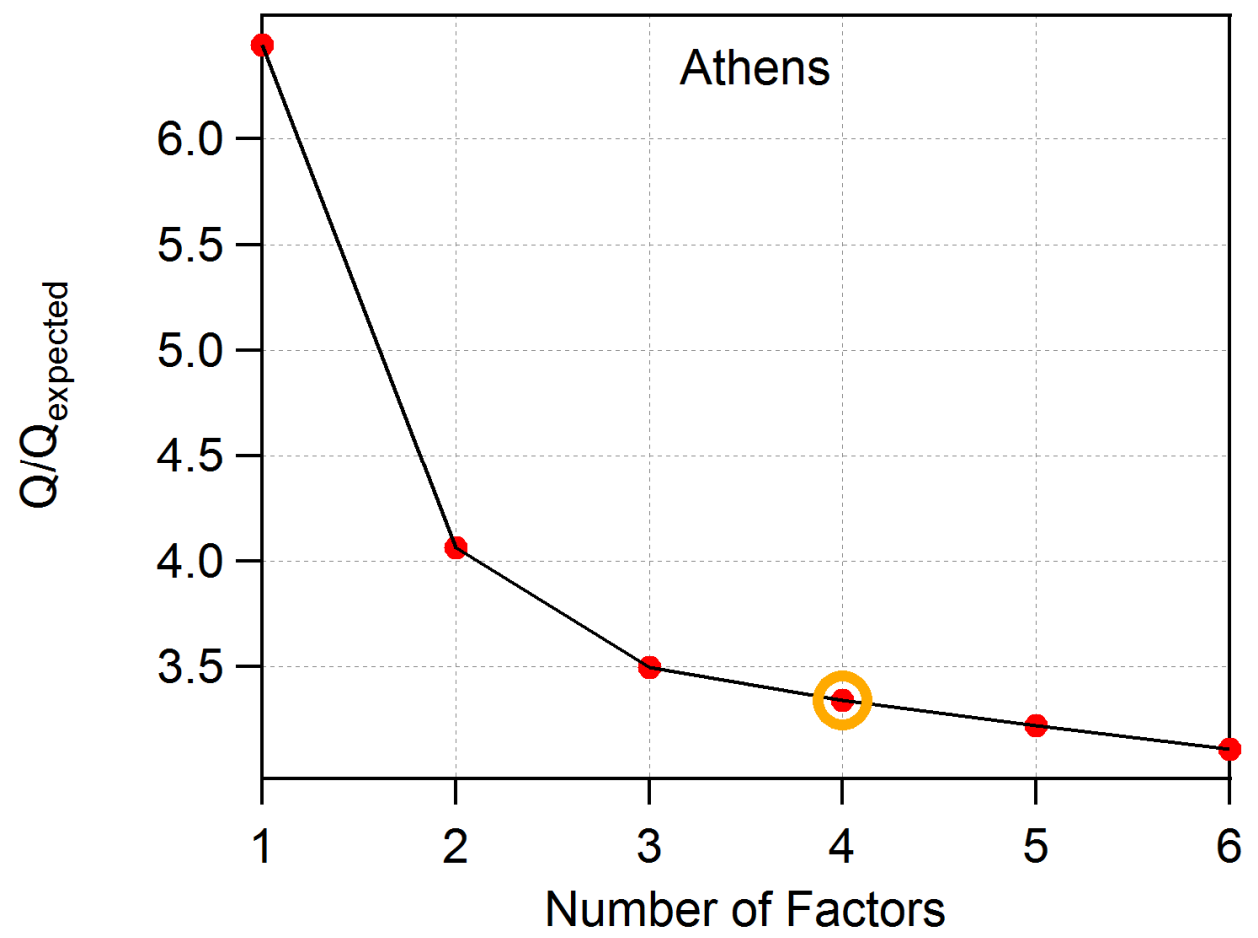

Figure S27. Q/Q $\mathrm{Q}_{\text {expected }}$ versus the number of PMF factors for Athens. 

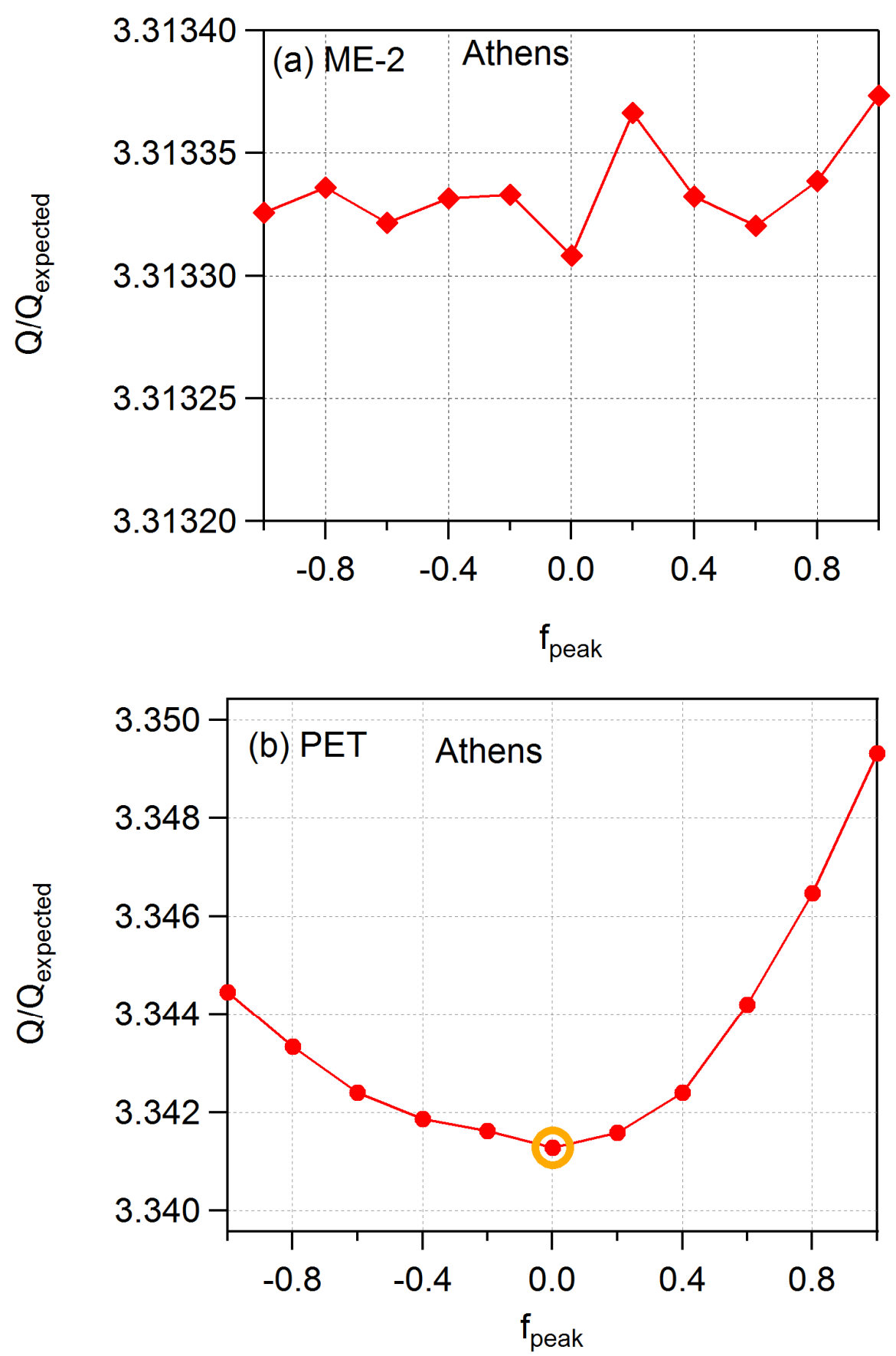

Figure S28. Q/Q $\mathrm{Q}_{\text {expected }}$ for $f_{\text {peaks }}-1$ to 1 for a 4 factor solution for Athens using: (a) ME-2 and (b) PET. For ME-2 all the solutions result in similar Q/Q expected values. Using PET the minimum $\mathrm{Q} / \mathrm{Q}_{\text {expected }}$ corresponds to $f_{\text {peak }}=0$. 

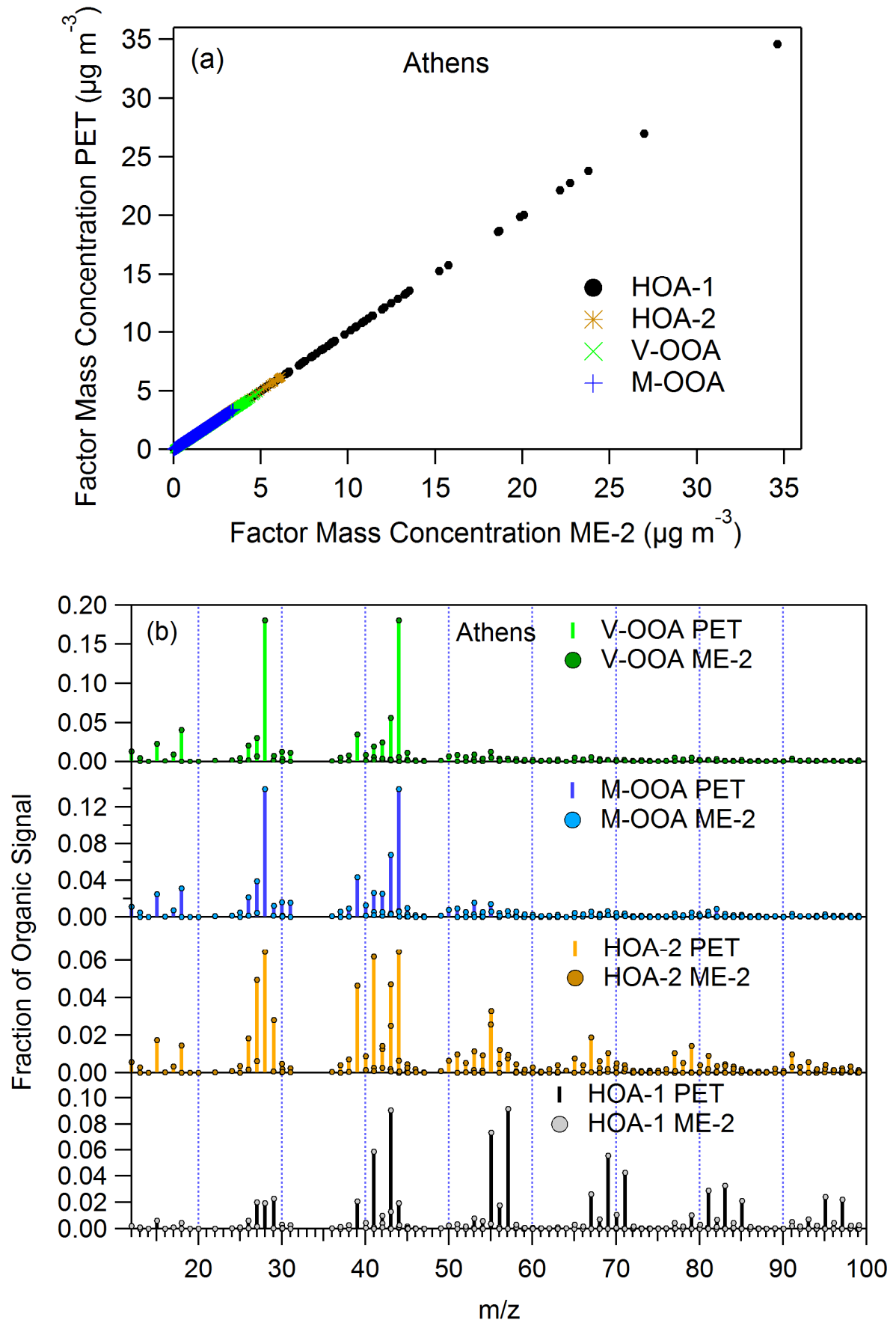

Figure S29. (a) Comparison and (b) the mass spectra of the 4 factors calculated by PET and ME- 2 for Athens. The PET factors are almost identical to the 4 factors obtained by ME-2. 

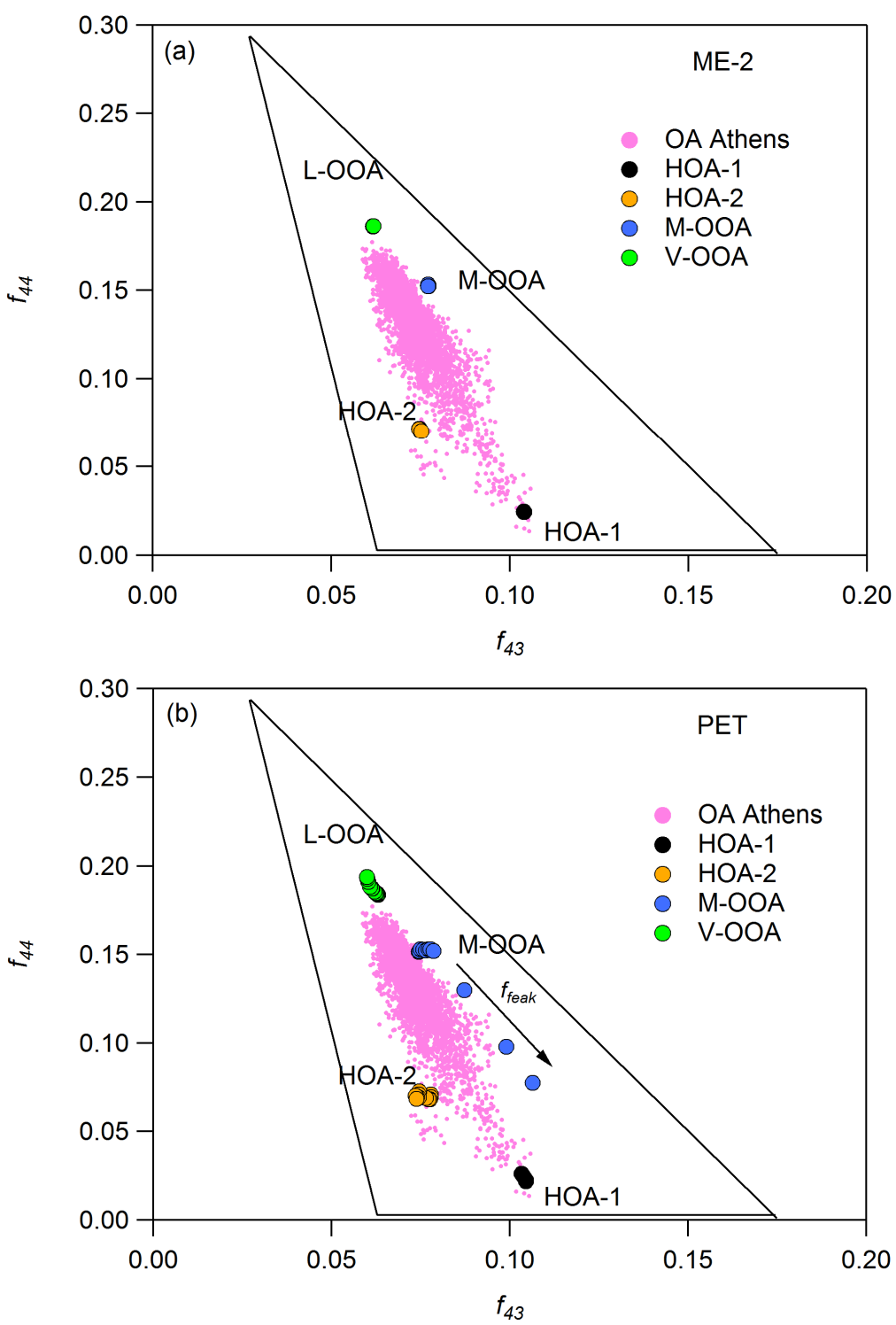

Figure S30. $f_{44}$ versus $f_{43}$ for the 4 factors found in Athens for $f_{\text {peaks }}-1$ to 1 using: (a) ME2 and (b) PET software. 


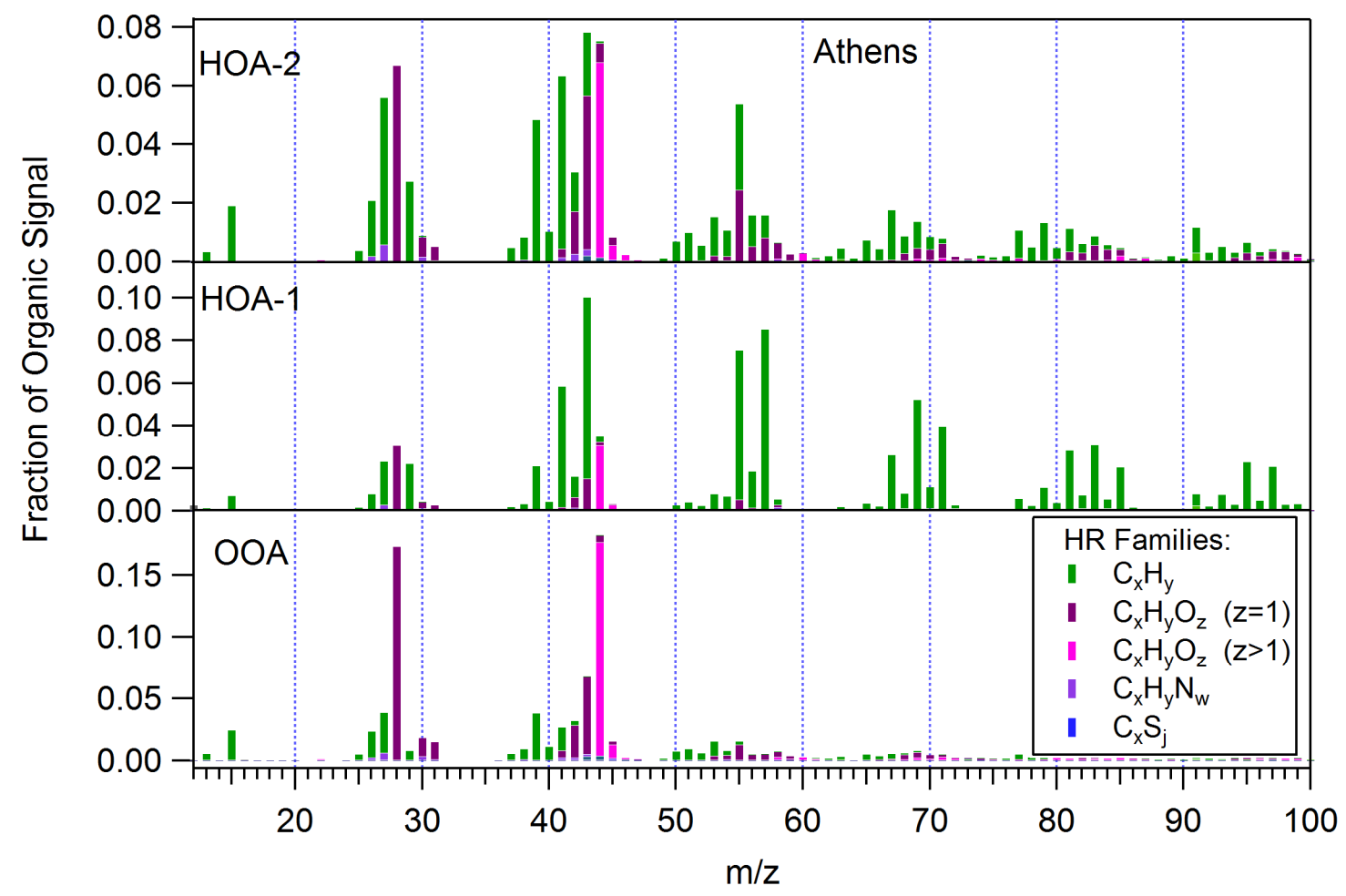

Figure S31. The 3-factor PMF solution for $f_{\text {peak }}=0$ for Athens. 

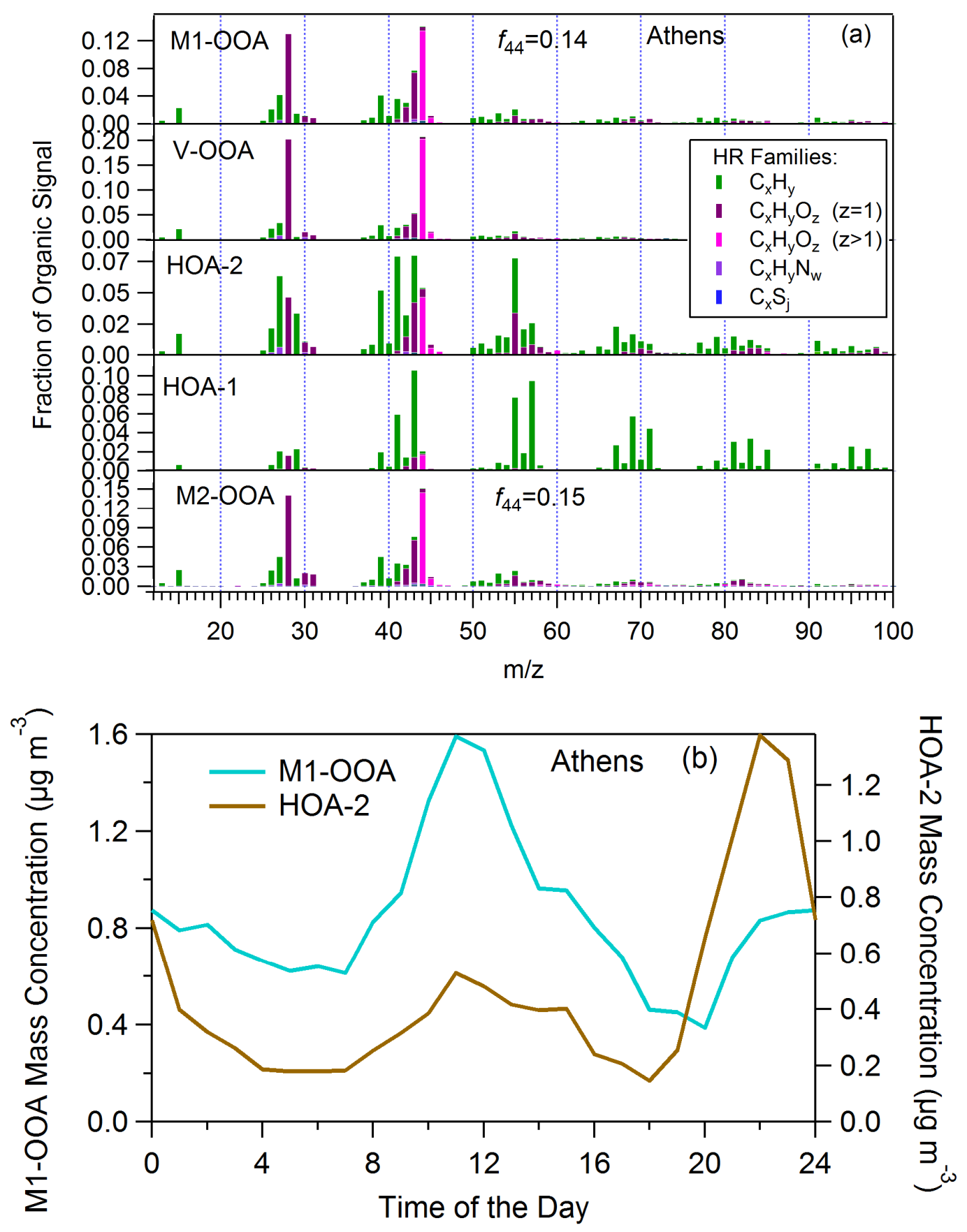

Figure S32. (a) The 5-factor PMF solution for 11 out of 20 seeds for Athens. The MOOA is split into 2 factors with similar $f_{44}(0.14$ for M1-OOA and 0.15 for M2-OOA. (b) The diurnal profile of M1-OOA is similar to the HOA-2 profile. 

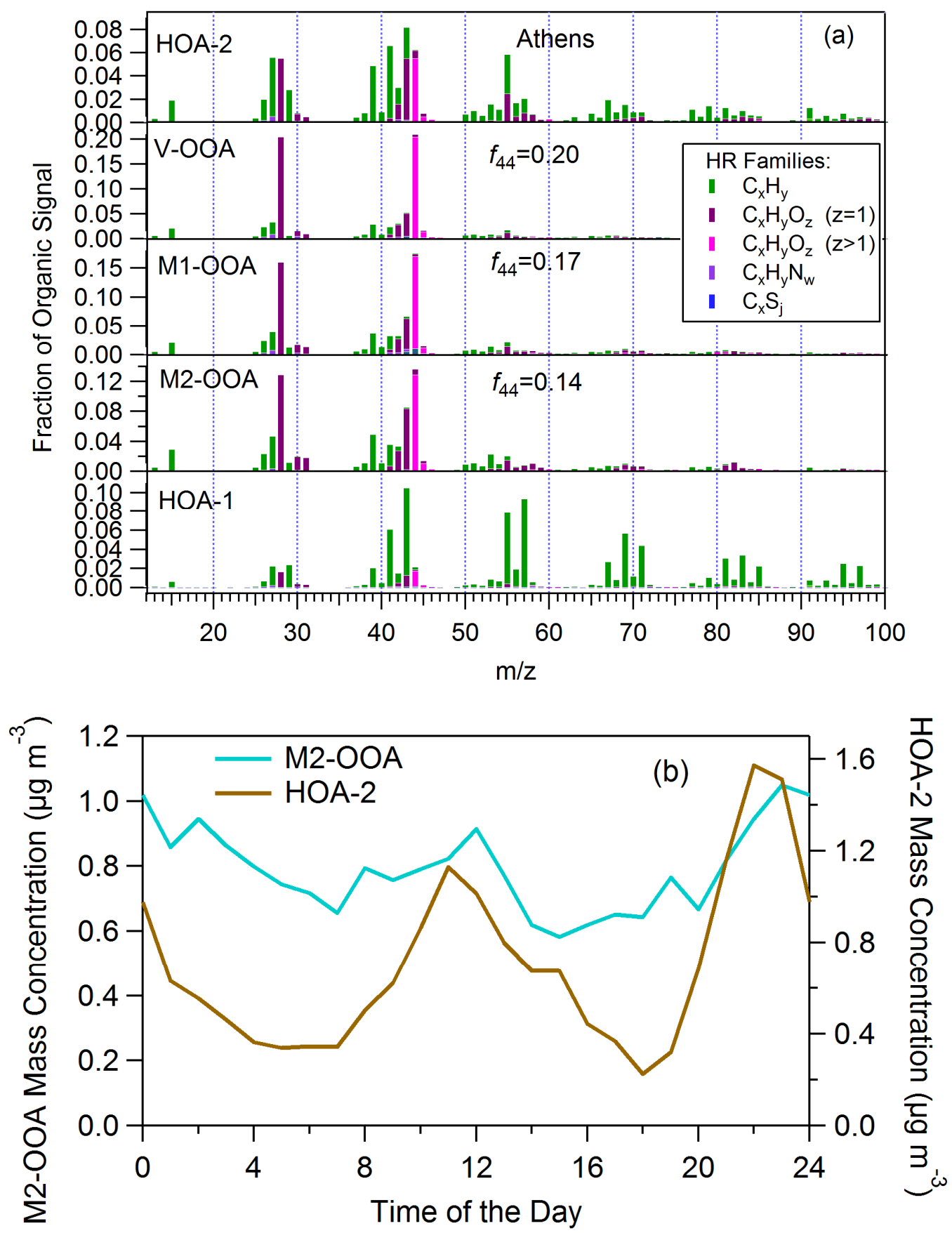

Figure S33. (a) The 5-factor PMF solution for 9 out of 20 seeds for Athens. The OOA is divided into 3 parts with $f_{44}: 0.20,0.17$ and 0.14 correspondingly. (b) The M2-OOA profile resembles the HOA-2 profile. 


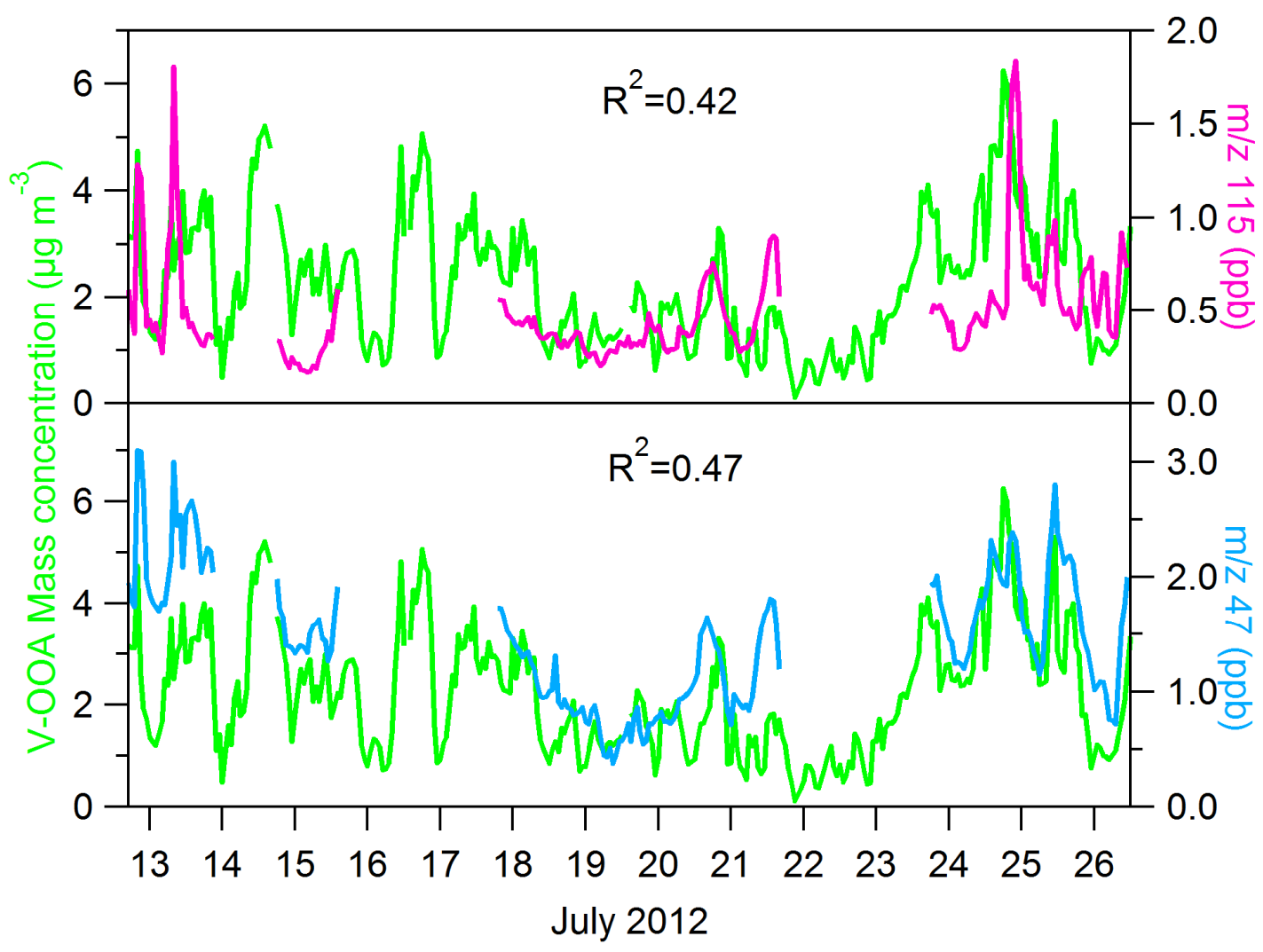

Figure S34: Time series of Athens V-OOA compared to the time series of $m / z$ 's 115 (heptanal) and 47 (formic acid). 


\section{Rose plots for Athens}

Rose plot analysis showed that $\mathrm{NO}_{\mathrm{x}}, \mathrm{BC}$ and benzene had the same origin but HOA-1 did not. An example is given below for the time period 07:00-10:00 LT.
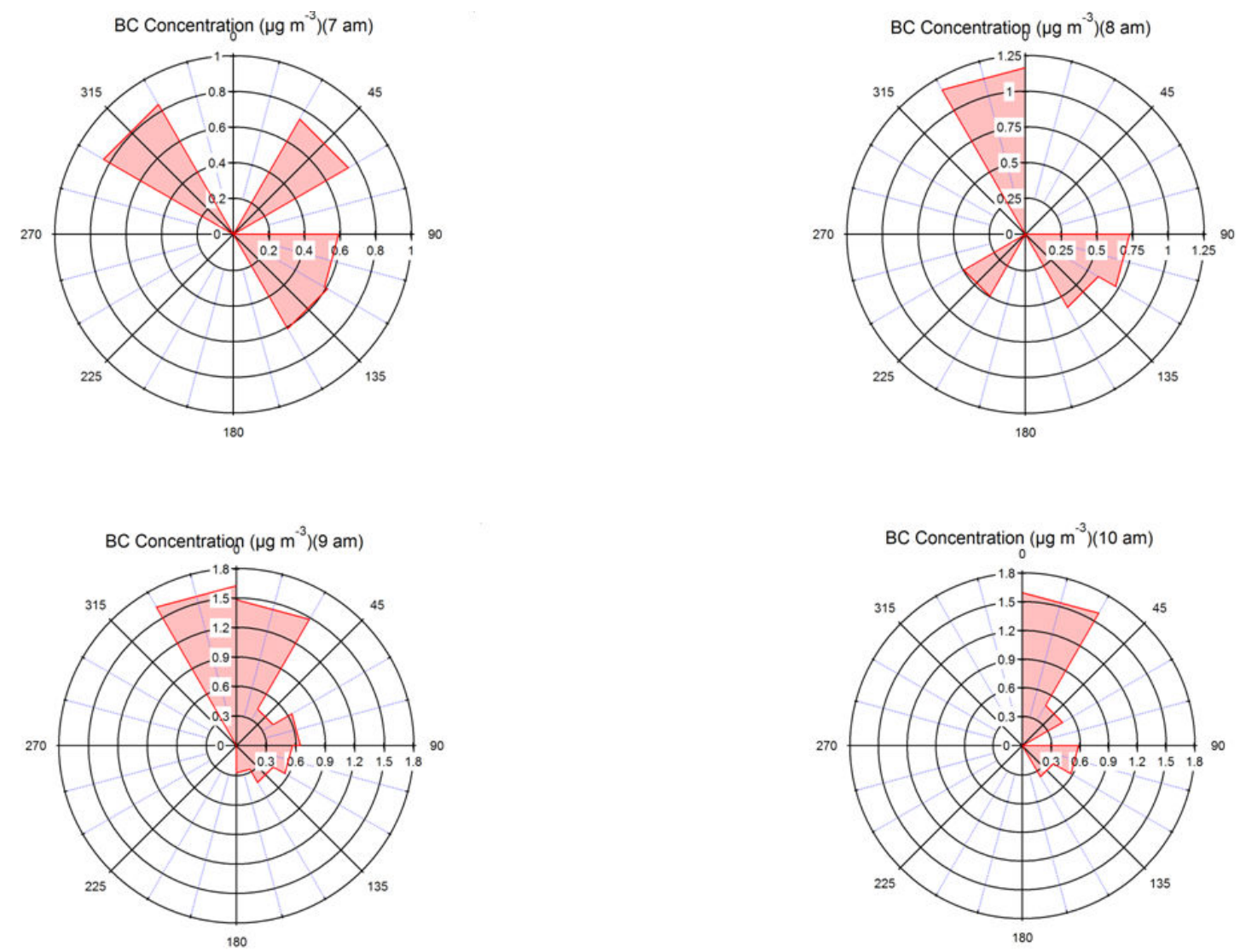

Figure S35. Rose plots for BC for 7:00-10:00 LT for wind speeds greater than $1 \mathrm{~m} \mathrm{~s}^{-1}$. 

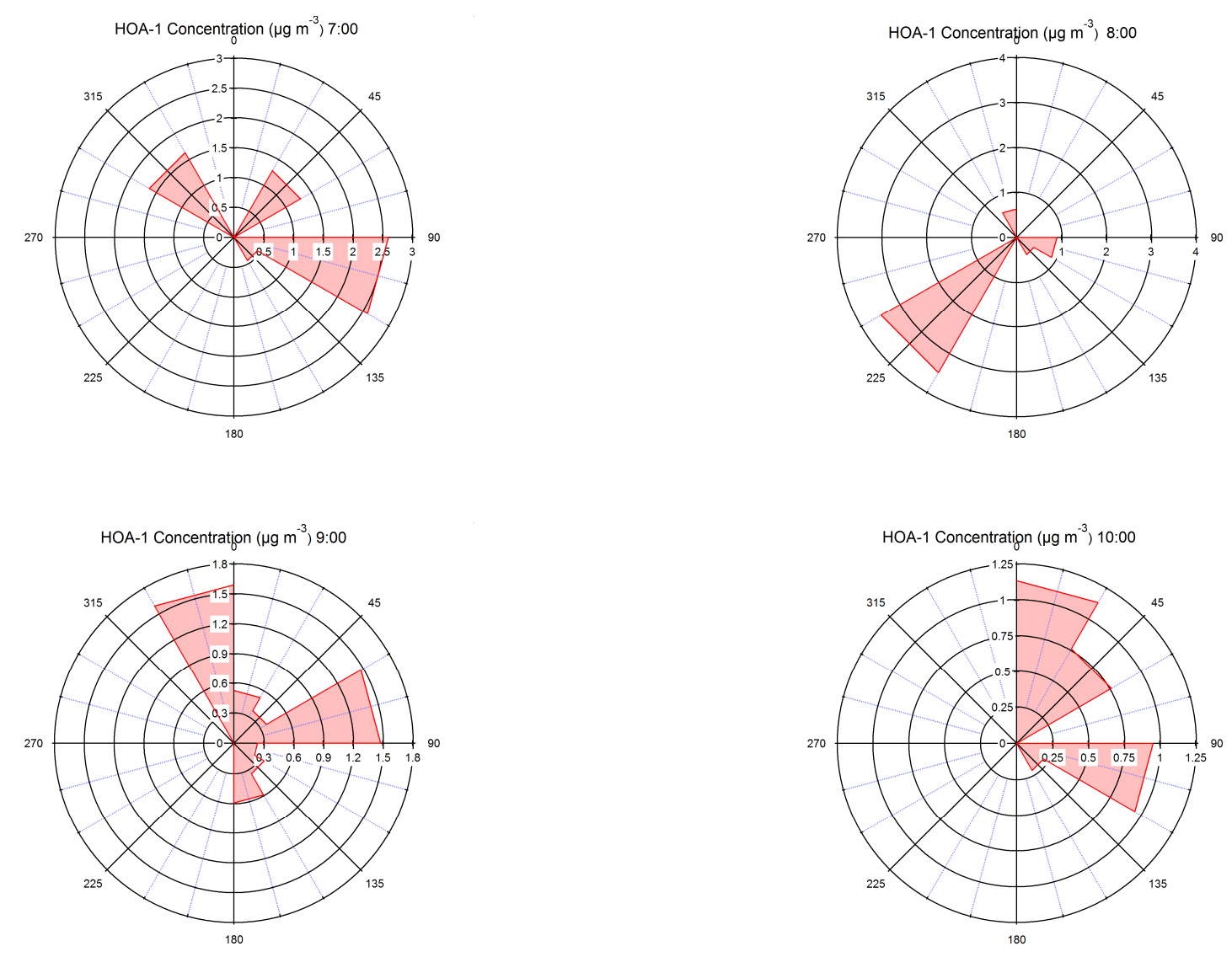

Figure S36. Rose plots for HOA-1 for 7:00-10:00 LT for wind speeds greater than $1 \mathrm{~m} \mathrm{~s}^{-}$ 1. 

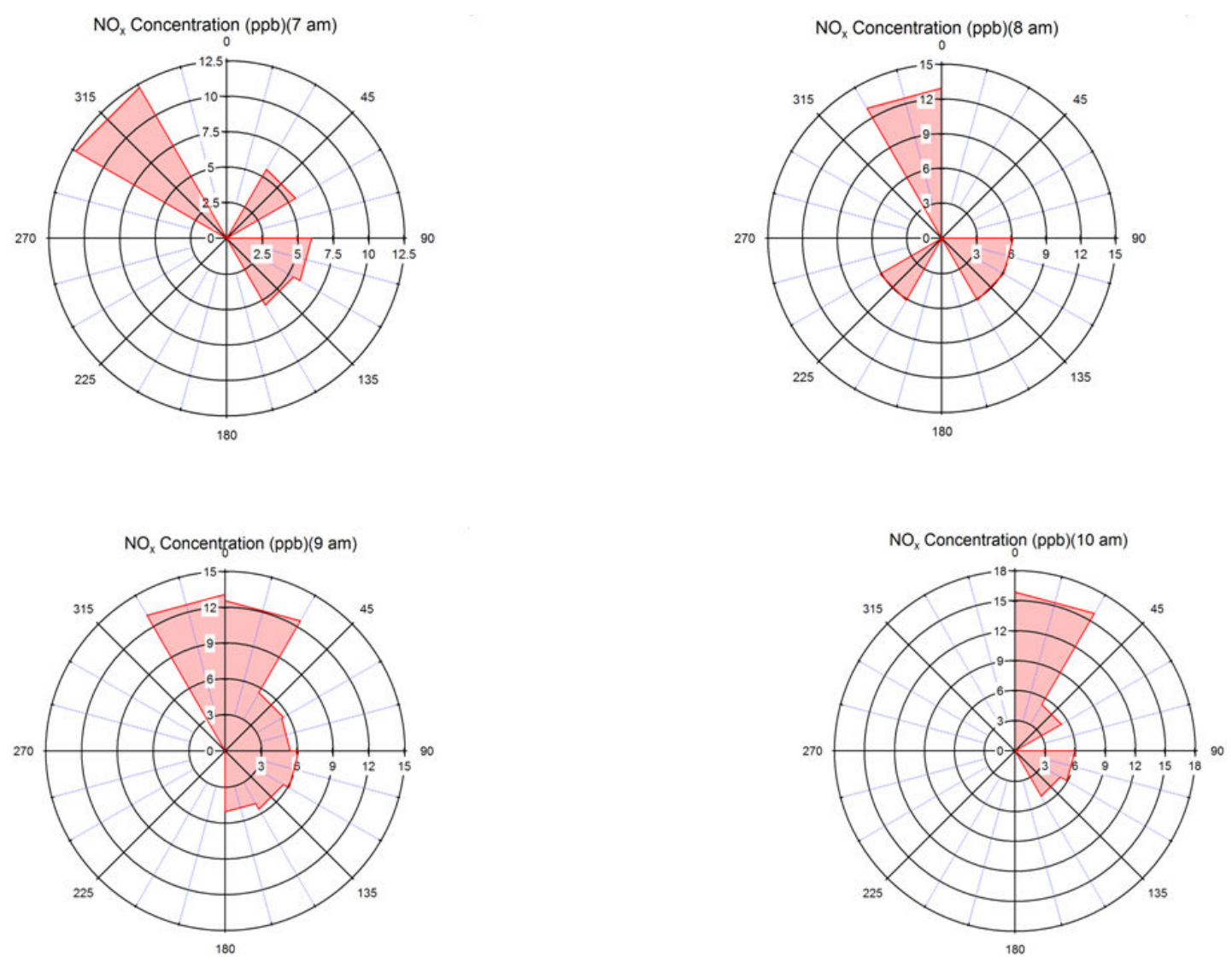

Figure S37. Rose plots for $\mathrm{NO}_{\mathrm{x}}$ for 7:00-10:00 LT for wind speeds greater than $1 \mathrm{~m} \mathrm{~s}^{-1}$. 

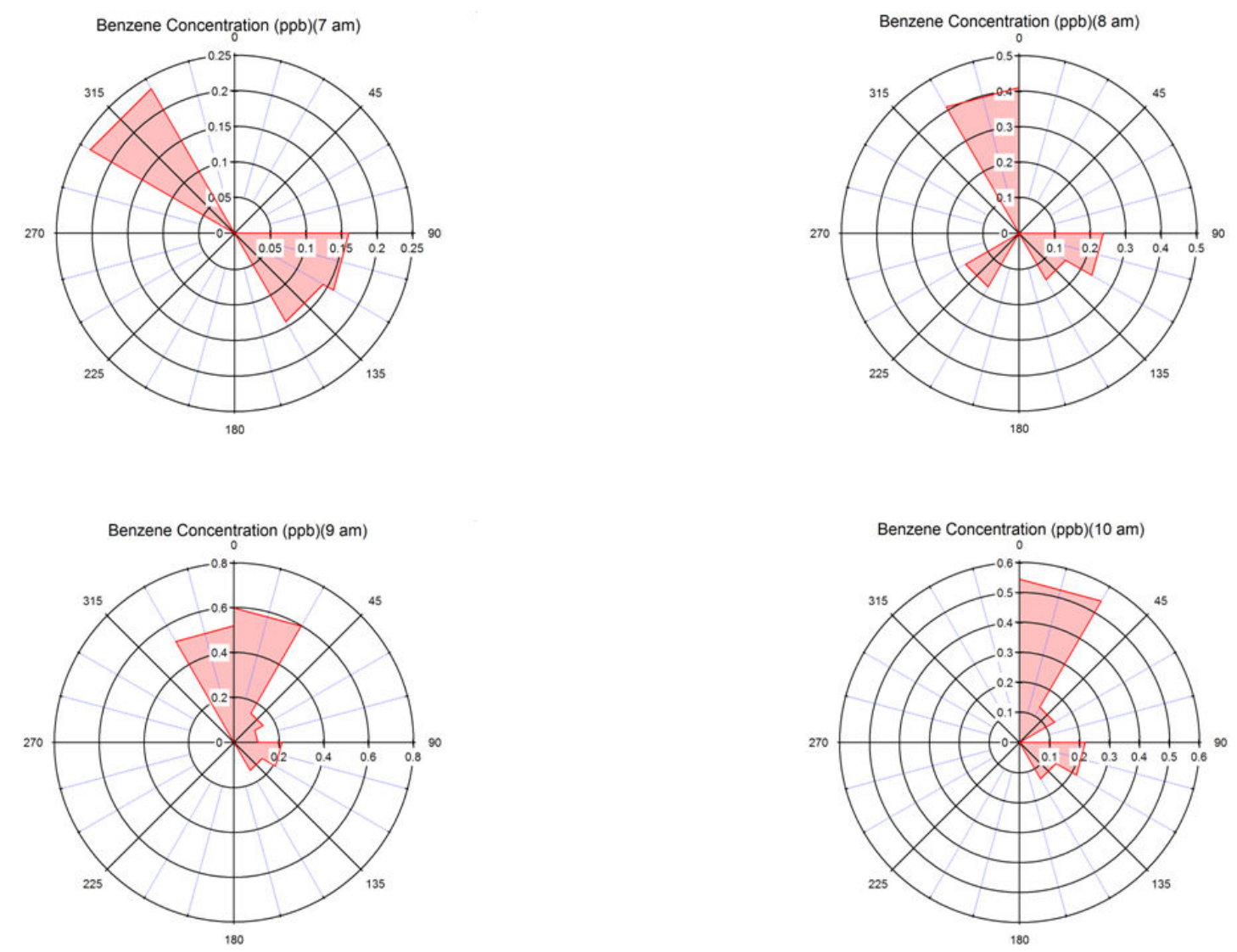

Figure S38. Rose plots for benzene for 7:00-10:00 LT for wind speeds greater than $1 \mathrm{~m}$ $\mathrm{S}^{-1}$. 


\section{Ng Triangle}

All Patras and Athens data fall within the Ng triangle.

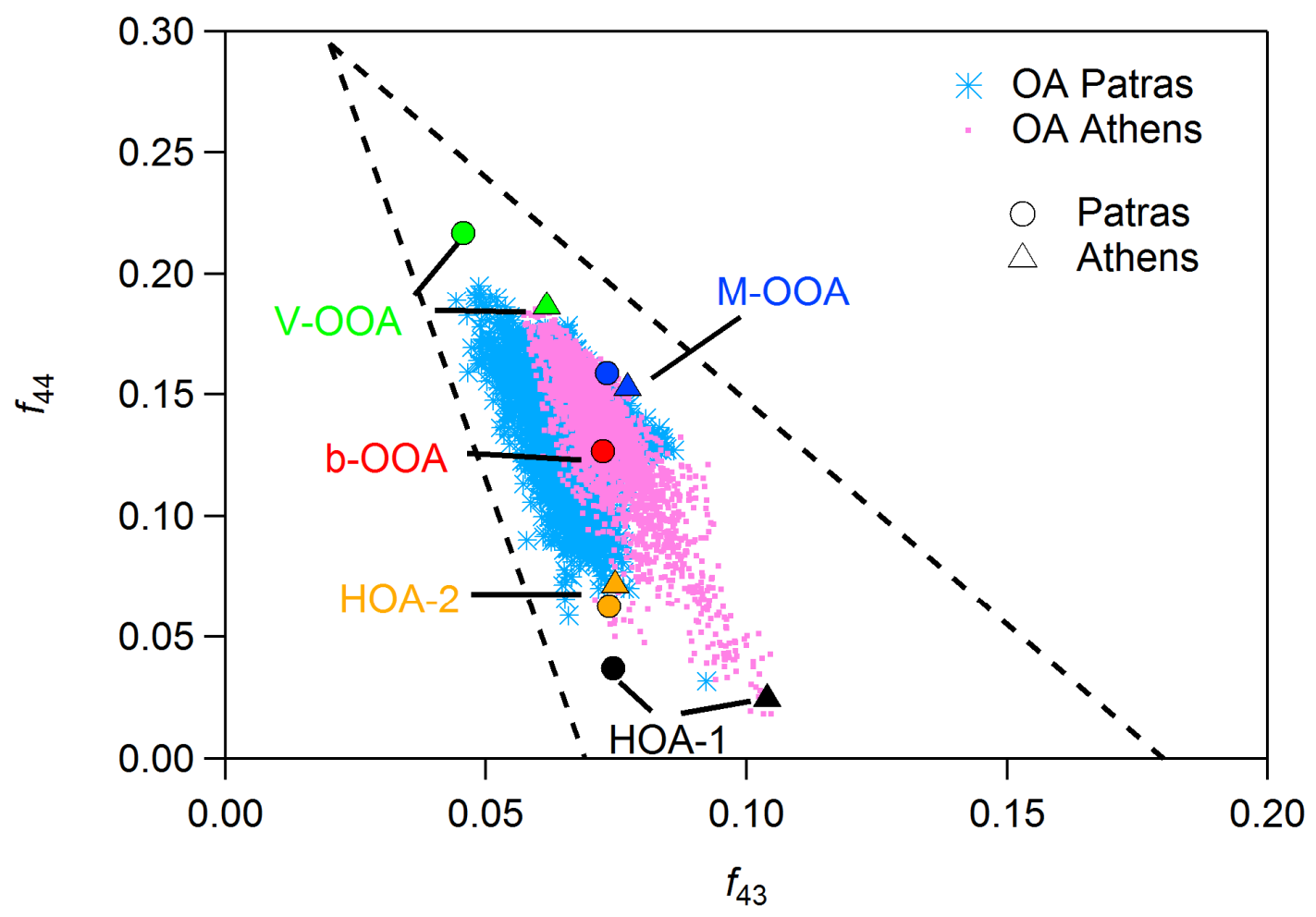

Figure S39. Patras (circles) and Athens (triangles) factor locations in the $\mathrm{Ng}$ et al. (2010) triangle. In both cases OA fall within the triangle. All the measurements in Patras (blue symbols) and Athens (pink symbols) are also shown. 


\section{FLEXPART analysis}

In Patras study most of the aerosol originated from continental Greece, while during the measurements in Athens the majority of the aerosol had spent considerable time above the Aegean Sea.
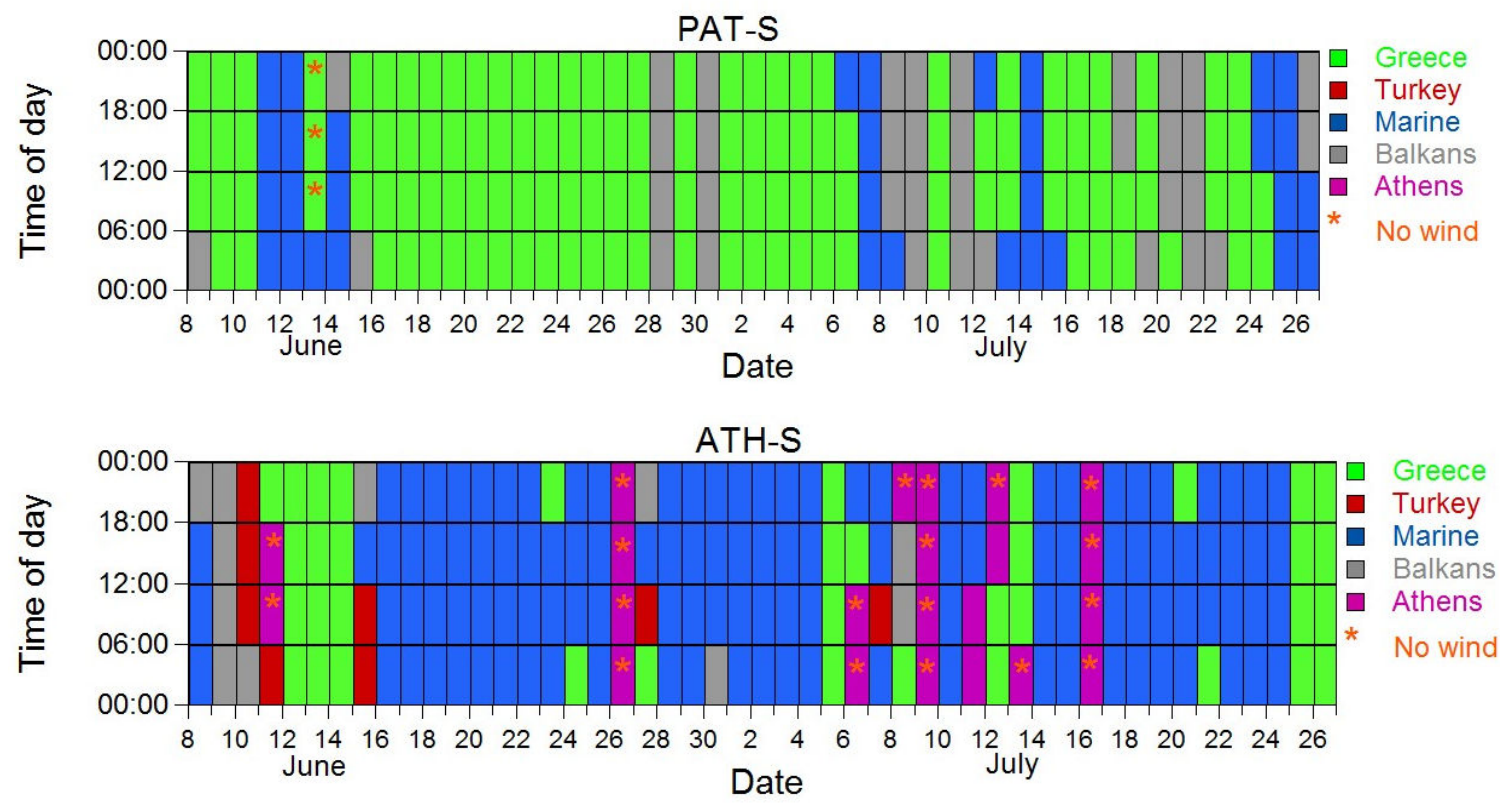

Figure S40: FLEXPART analysis (Stohl et al., 2005) for Patras and Athens campaigns. 


\section{References}

Aiken, A. C., Salcedo, D., Cubison, M. J., Huffman, J. A., DeCarlo, P. F., Ulbrich, I. M., Docherty, K. S., Sueper, D., Kimmel, J. R., Worsnop, D. R., Trimborn, A., Northway, M., Stone, E. A., $\quad$ Schauer, J. J., $\quad$ Volkamer, R. M., $\quad$ Fortner, E., $\quad$ de Foy, B., $\quad$ Wang, J., Laskin, A., Shutthanandan, V., Zheng, J., Zhang, R., Gaffney, J., Marley, N. A., ParedesMiranda, G., Arnott, W. P., Molina, L. T., Sosa, G., and Jimenez, J. L.: Mexico City aerosol analysis during MILAGRO using high resolution aerosol mass spectrometry at the urban supersite (T0) - Part 1: Fine particle composition and organic source apportionment, Atmos. Chem. Phys., 9, 6633-6653, 2009.

Canonaco, F., Crippa, M., Slowik, J. G., Baltensperger, U., and Prévôt, A. S. H.: SoFi, an IGOR-based interface for the efficient use of the generalized multilinear engine (ME-2) for the source apportionment: ME-2 application to aerosol mass spectrometer data, Atmos. Meas. Tech., 6, 3649-3661, 2013.

Crippa M., El Haddad I., Slowik J., G., DeCarlo P. F., Mohr, C., Heringa, M., F, Chirico, R., Marchand, N., Sciare, J., Urs, B., and Prévôt, A. S. H.: Identification of marine and continental aerosol sources in Paris using high resolution aerosol mass spectrometry, J. Geophys. Res, doi: 118, 1950-1963, doi: 10.1002/jgrd.50151, 2013.

Docherty, K. S., Aiken, A. C., Huffman, J. A., Ulbrich, I. M., DeCarlo, P. F., Sueper, D., Worsnop, D. R., Snyder, D. C., Peltier, R. E., Weber, R. J., Grover, B. D., Eatough, D. J., Williams, B. J., Goldstein, A. H., Ziemann, P. J., and Jimenez, J. L.: The 2005 Study of Organic Aerosols at Riverside (SOAR-1): Instrumental intercomparisons and fine particle composition, Atmos. Chem. Phys., 11, 12387-12420, 2011.

Draxler, R. R., and Rolph, G. D., 2013. HYSPLIT (HYbrid Single-Particle Lagrangian Integrated Trajectory) Model access via NOAA ARL READY Website (http://ready.arl.noaa.gov/HYSPLIT.php). NOAA Air Resources Laboratory, Silver Spring, MD. 
Farmer, D.K., Matsunaga, A., Docherty, K. S., Surratt, J. D., Seinfeld, J. H., Ziemann P. J., and Jimenez, J. L., Response of an aerosol mass spectrometer to organonitrates and organosulfates and implications for atmospheric chemistry. Proceedings of the National Academy of Sciences, 107, 6670-6675, doi: 10.1073/pnas.0912340107, 2010.

Kostenidou, E., Pathak, R. K., and Pandis, S. N.: An algorithm for the calculation of secondary organic aerosol density combining AMS and SMPS data, Aerosol Sci. Technol., 41, 1002-1010, 2007.

Lanz, V. A., Alfarra, M. R., Baltensperger, U., Buchmann, B., Hueglin, C., Szidat, S., Wehrli, M. N., Wacker, L., Weimer, S., Caseiro, A., Puxbaum, J., and Prévôt, A. S. H.: Source attribution of submicron organic aerosols during wintertime inversions by advanced factor analysis of aerosol mass spectra, Environ. Sci. Technol., 42, 214-220, 2008.

Mohr, C., DeCarlo, P. F., Heringa, M. F., Chirico, R., Slowik, J. G., Richter, R., Reche, C., Alastuey, A., Querol, X., Seco, R., Penuelas, J., Jimenez, J. L., Crippa, M., Zimmermann, R., Baltensperger, U., and Prevot, A. S. H.: Identification and quantification of organic aerosol fromcooking and other sources in Barcelona using aerosol mass spectrometer data, Atmos. Chem. Phys., 12, 1649-1665, 2012.

Stohl, A., Forster, V., Frank, A., Seibert, P., \& Wotawa, G.: Technical Note: The Lagrangian particle dispersion model FLEXPART version 6.2, Atmos. Chem. Phys., 5, 2461-2474, 2005.

Sun, Y. L., Zhang, Q., Schwab, J. J., Demerjian, K. L., Chen, W. N., Bae, M. S., Hung, H. M., Hogrefe, O., Frank, B., Rattigan, O. V., and Lin, Y. C.: Characterization of the sources and processes of organic and inorganic aerosols in New York city with a highresolution time-of-flight aerosol mass spectrometer, Atmos. Chem. Phys., 11, 1581-1602, 2011. 
Ulbrich, I. M., Canagaratna, M. R., Zhang, Q., Worsnop, D. R., and Jimenez, J. L.: Interpretation of organic components from Positive Matrix Factorization of aerosol mass spectrometric data, Atmos. Chem. Phys., 9, 2891-2918, 2009. 